\title{
Article \\ Solvency Regulation-An Assessment of Basel III for Banks and of Planned Solvency III for Insurers
}

\author{
Peter Zweifel
}

Citation: Zweifel, Peter. 2021

Solvency Regulation-An

Assessment of Basel III for Banks and of Planned Solvency III for Insurers. Journal of Risk and Financial Management 14: 258. https:// doi.org/10.3390/jrfm14060258

Academic Editors: Ana Lozano-Vivas and Shigeyuki Hamori

Received: 20 April 2021

Accepted: 2 June 2021

Published: 8 June 2021

Publisher's Note: MDPI stays neutral with regard to jurisdictional claims in published maps and institutional affiliations.

Copyright: (C) 2021 by the author. Licensee MDPI, Basel, Switzerland. This article is an open access article distributed under the terms and conditions of the Creative Commons Attribution (CC BY) license (https:// creativecommons.org/licenses/by/ $4.0 /)$
Department of Economics, University of Zurich, Rämistrasse 71, 8006 Zürich, Switzerland; peter.zweifel@econ.uzh.ch

\begin{abstract}
Basel III, regulating the solvency of banks, is to be fully implemented by 2027 while Solvency III directed at insurers is being prepared. In view of past experience, it will be closely modelled after Basel III. This raises two questions. (i) Will Basel III and Solvency III be more successful than their predecessors? (ii) Is it appropriate to continue regulating the solvency of banks and insurers in the same way? The first question is motivated by an earlier finding that Basel I and II risked inducing more rather than less risk-taking by banks, which also holds for Solvency I and II w.r.t. insurers. The methodology applied was to determine the slope of an endogenous perceived efficiency frontier (EPEF) in $(\hat{\mu}, \hat{\sigma})$-space derived from banks' and insurers' optimal adjustment to exogenous changes, in expected returns $d \bar{\mu}$ and volatility $d \bar{\sigma}$ on the capital market. Both Basel I and II and Solvency I and II neglected the impact of these developments on banks' and insurers' EPEF. This neglect had the effect of steepening the EPEF, causing senior management to opt for an increased rather than reduced value of $\hat{\sigma}$, and hence a lower solvency level. This issue is resolved by Basel III (Principle 5), which requires banks to take developments in the capital market into account in the formulation of their business strategies designed to ensure solvency. In combination with increased capital requirements, this is shown to result in a reduced slope of their EPEF and hence a reduced risk exposure. However, planned Solvency III may cause the EPEF of highly capitalized insurance companies to become steeper, with a concomitant decrease in their risk-taking and an increase of their solvency level. The second question, concerning the appropriateness of the uniformity of solvency regulation directed at banks and insurers, arises because the parameters determining the slope of the respective EPEF are found to crucially differ. Therefore, the uniformity of Basel and Solvency norms creates the risk of a mistaken regulatory focus.
\end{abstract}

Keywords: regulation; banks; insurers; Basel I; Basel II; Basel III; Solvency I; Solvency II; Solvency III

JEL Classification: G15; G21; G28; L51

\section{Introduction}

Basel III regulation, designed to further enhance banks' solvency, will be fully implemented by 2027 (Basel Committee on Banking Supervision 2017), while preparations are under way for Solvency III directed at insurance companies (Van Hulle 2018). In view of past experience, Solvency III will be modelled closely after Basel III. This article seeks to answer two questions. First, are Basel III and planned Solvency III likely to attain their stated objective of enhancing banks' and insurers' solvency? This question is motivated by the finding of Zweifel et al. (2015) that Basel I (and to a lesser extent Basel II) might well induce banks to adopt a more rather than less risky position, resulting in a lower level of solvency. The same effect was predicted by Zweifel (2015) regarding insurers, for Solvency I and II. The methodology adopted was to determine banks' and insurers' optimal adjustments to exogenous changes in expected returns $d \bar{\mu}$ and volatility $d \bar{\sigma}$ on the capital market. The concomitant reshuffling of their assets results in changed values $d \hat{\mu}$ and $d \hat{\sigma}$, which determine the slope of an endogenous perceived efficiency frontier (EPEF) in $(\hat{\mu}, \hat{\sigma})$-space. 
However, Basel I and Basel II as well as Solvency I and Solvency II neglected the impact of exogenous developments in the capital market on banks' and insurers' EPEF. This neglect was shown to result in a steepening of the EPEF, which in turn leads senior management to opt for a higher rather than lower value of $\hat{\sigma}$, and hence a lower level of solvency. By way of contrast, this contribution leads to the conclusion that Basel III and planned Solvency III (at least for insurers with little solvency capital) may well achieve their stated objective of enhancing solvency. The reason is that now the neglect of changes originating in the capital market is lifted, combined with an increase in capital requirements.

As to the second question, the continuing uniformity of solvency regulation directed at banks and insurers is found to be unjustified. The slope of an insurer's EPEF depends on parameters that differ from those determining a bank's EPEF. This creates the risk of a misplaced regulatory focus; "one size (of regulation) does not fit all".

These findings derive from two models of behavior that depict a bank (an insurer, respectively) in the process of their sequential decision-making. In period 0 , exogenous changes in expected returns $d \bar{\mu}$ and volatility $d \bar{\sigma}$ in the capital market impinge on their investment division (the Division henceforth). A typical cause could be investments made in the previous period that turn out to have a lower rate of return or a higher volatility than expected. In period 1, the Division adjusts its solvency level in response to these shocks, in ways predicted by the maximization of its risk-adjusted rate of return on capital and comparative-static analysis. In period 2, the changed solvency level in turn acts like an exogenous change causing the Division to internally develop an EPEF in $(\hat{\mu}, \hat{\sigma})$-space, on which senior management chooses the optimum in period 3 , taking into account its degree of risk aversion.

This EPEF is modified by solvency regulation. It will be argued that both Basel I and II and Solvency I and II neglected the fact that the relationship between the solvency capital and solvency varies with exogenous changes in expected returns on invested capital and their volatility in the capital market. Through their neglect of this variability Basel I and II as well as Solvency I and II had the unexpected consequence of increasing the slope of the bank's (insurer's, respectively) EPEF. This, consequently induced senior management to opt for higher expected returns $(\hat{\mu})$ but higher volatility $(\hat{\sigma})$ and hence a lower level of solvency (Zweifel et al. 2015; Zweifel 2015). This deficiency is corrected by Basel III which explicitly requires banks to take account of developments in the capital markets (dubbed "interest rate risk") in the formulation of their business strategies designed to ensure solvency (Basel Committee on Banking Supervision 2016, Principle 5). In addition, Basel III stipulates a maximum leverage ratio, which means an increased amount of solvency capital for most banks. These innovations are shown to reduce the slope of the bank's EPEF, inducing senior management to opt for less volatility, an effect that is also found to hold as well at least for insurance companies with little solvency capital.

However, the issue raised in the second question remains-developments in the capital market impinge on banks and insurers in quite different ways. In the case of banks, they modify the relationship between the interest they have to pay on their deposits and solvency, whereas in the case of insurers, they modify the relationship between their premium income and solvency. This difference argues against regulating banks and insurers in the same way. In sum, Basel III and planned Solvency III constitute an improvement over Basel I and II and over Solvency I and II, provided regulatory focus is on the appropriate parameters.

This paper is structured as follows. Section 2 contains a review of the pertinent literature, which in principle justifies solvency regulation in view of negative externalities of an insolvency but also points out its own cost. In Section 3, the bank's (the insurer's, respectively) investment division (the Division) sets solvency, by balancing its marginal return in terms of lowered cost of refinancing, and marginal cost in terms of capital tied that would have more lucrative alternative uses (period 0). In Section 4, exogenous changes of expected returns and volatility disturb the respective optima, causing the Division to adjust the solvency level (period 1). These adjustments are derived using comparative-static analysis; however, there can be only one adjustment of solvency. In Section 5, this single 
adjustment in turn causes the Division to reshuffle the bank's (insurer's, respectively) assets, which gives rise to an endogenous perceived efficiency frontier (EPEF) in period 2. In Section 6, senior management chooses its optimum on the EPEF, taking account of its degree of risk aversion (period 3). The "deformation" of the EPEF caused by regulation is derived in Section 7; it has the consequence of management opting for more rather than less volatility and hence a lower level of solvency. In Section 8, this deformation is voided by Basel III and planned Solvency III. In addition, the increased capital requirement is shown to reduce the slope of the EPEF, which is conducive to a choice of reduced volatility as compared to the no-regulation benchmark by banks (and insurance companies with little solvency capital). The limitations of this study are pointed out in Section 9, while a summary and conclusions follow in Section 10.

\section{Literature Review}

\subsection{Solvency Regulation of Banks}

The solvency regulation of banks has traditionally been justified by the external costs of insolvency. However, proponents of the Capital Asset Pricing Model have argued that to well-diversified investors, the solvency of a particular bank does not matter because they can hedge against (almost) all risks. In contrast, for little-diversified investors (among them, ordinary consumers holding deposits with the bank), overall risk is relevant, which importantly includes the risk of insolvency (Goldberg and Hudgins 1996, 2002; Park and Peristiani 1998; Jordan 2000). In the view of Option Pricing Theory, shareholders of the bank in fact hold a put option written by the other stakeholders (notably creditors) of the bank (Merton 1974, 1977; Jensen and Meckling 1976).

When a solvency risk materializes, internal costs are borne by the bank's shareholders, who see the value of their shares drop to zero. Due to reputation effects, the bank is unlikely to be in business again (Smith and Stulz 1985, pp. 395-96; Stulz 1996, pp. 9-12). As to the external costs of insolvency, it may trigger a bank run (Diamond and Dybvig 1983; Jacklin and Bhattacharya 1988; Bauer and Ryser 2004), burdening depositors who are late to withdraw their funds with at least a partial loss of their assets. Since banks are also among these depositors, they could be driven into bankruptcy by the insolvent competitor (Lang and Stulz 1992; Furfine 2003). Moreover, owners and creditors of banks in general are led to re-evaluate the estimated risk of insolvency. Their demand for a higher rate of interest from their banks drives up the cost of refinancing. There is a substantial body of empirical research, substantiating this claim (Flannery and Sorescu 1996; Park and Peristiani 1998; Covitz et al. 2004).

In view of external cost, the solvency level opted for by a bank in its own interest is too low from a societal perspective. However, public intervention designed to redress the balance may lack effectiveness. For instance, Koehn and Santomero (1980) find the imposition of an equity-to-assets ratio to be ineffective on average. Relatively safe banks become safer, while risky ones espouse more risk to make up for decreased leverage. In Kim and Santomero (1988), emphasis is on the choice of appropriate risk weights in the determination of what has since become risk-based capital. The authors argue that regulation may end up imposing suboptimal weights.

Public intervention even runs the risk of engendering cost itself by inducing unintended behavioral adjustments. While Rochet (1992) favors minimum capital requirements in view of banks' limited liability which makes them risk-lovers, John et al. (2000) argue that managers may be led by their compensation plans to shift risk to outside financiers, despite U.S. capital-based regulation introduced in 1991. Indeed, Hogan (2021) finds that out of 27 pertinent rules proposed by U.S. regulators between 1986 and 2018, only nine were subject to a cost-benefit analysis, five of which arrived at a favorable (albeit nonquantitative) assessment. In two cases, the cost of regulation definitely exceeded its benefit. In his analysis of Basel II, Repullo (2004) recognized that the market for deposits is likely imperfectly competitive. He derived conditions for two Nash equilibria to obtain, one in which banks invest in riskless and another where they invest in risky assets. While capital 
requirements for risky assets do enlarge the parameter space of the "prudent" equilibrium, depositors (rather than shareholders) bear the burden of regulation in the guise of lower interest rates. In Harris et al. (2014), banks make up for their reduction in lending capacity due to high capital requirements, by leaving even good projects to unregulated non-bank investors, which is inefficient. Pointing to bank-specific problems of governance, Mülbert (2009) even argues that prudential regulation of the Basel I and II type may make banking crises more likely.

\subsection{Solvency Regulation of Insurers}

Ever since Cummins (1988), solvency regulation of insurers has been justified by the claim that they engage in excessive risk-taking, similar to banks. However, there are again well-diversified investors who are not affected by the insolvency of a particular insurance company. Yet many policyholders are little diversified; in addition, they finance the shareholders' put option (Cummins and Phillips 2001; Zweifel et al. 2021, chp. 6.3). Especially in the case of life insurance, the loss of their claims due to insurer insolvency entails substantial external cost. In addition, the insolvent insurer may drive other financial institutions into insolvency, in particular through the coinsurance of large risks (Furfine 2003). As with banks, investors in the capital market may also revise their estimate of risk upward, causing the cost of capital of other insurers to increase. However, the insolvency of an insurer is unlikely to have repercussions throughout an economy, unlike a bank run (Cummins and Weiss 2014). In particular, cancelling a policy entails a high cost, because the customer is charged the considerable cost of acquisition.

The present contribution differs from the earlier literature in two ways. First, it clearly distinguishes Basel III regulation from its predecessors Basel I and Basel II (planned Solvency III from its Solvency I and Solvency I and Solvency II, respectively), using two simple models of behavior. Second, it introduces dynamics in the following way. Whereas earlier contributions focused on optima or equilibria (as in the case of Repullo (2004) and Harris et al. (2014)), here the bank's and the insurer's paths of adjustment from one optimum to the next are analyzed. Adjustment to exogenous shocks are shown to be conditioned by the solvency regulation of Basel I and II (Solvency I and II, respectively) type in an unexpected way, contrary to Basel III (planned Solvency III, respectively). In return, welfare implications are not spelled out (see Admati et al. (2013) for important considerations in this regard). Rather, the fact that banks and insurers may be induced to act against (in accordance with, respectively) the stated intentions of the regulator, is highlighted.

\section{The Divisions Optimize Solvency (Period 0)}

\subsection{The Bank's Investment Division Selects the Optimal Solvency Level}

This section considers a bank's investment division (the Division henceforth). Its task is to maximize the expected rate of return on risk-adjusted capital $R^{B}$ through its choice of solvency $S^{B}$. By assumption, senior management mandates the Division to act in a risk-neutral manner. Otherwise, it is conceivable that employee $\mathrm{R}$ (who is strongly risk averse) rejects funding a project that employee A (who has more of a risk appetite) would accept. Imposing risk neutrality on the Division avoids this type of inconsistency; risk preferences will enter in period 3 (Section 6) when the bank's senior management selects its preferred position on the $(\hat{\mu}, \hat{\sigma})$-efficiency frontier generated by the Division (assuming that it applies $(\mu, \sigma)$-analysis as an approximation despite the presence of skewness and kurtosis in returns).

While there is no need to define the objectives of Basel-type solvency regulation in a formal way, it may be thought of in terms of the likelihood of a shortfall (Leibowitz et al. 1992) or in terms of value-at-risk $(V a R)$ or expected value-at-risk (EVaR) concepts (however, see Artzner et al. (1999) for a critique, Krokhmal et al. (2001), who propose the conditional value at risk (CVar) as a so-called coherent alternative, and Heyde et al. (2006), who generalize the concept to a natural risk statistic). Whenever VaR, EVaR, or CVar increases, the 
solvency level can be said to decrease. Despite its deficiencies, the $V a R$ criterion continues to be used by Basel I to III and Solvency I and II, forcing banks and insurers to adhere to it as well. However, whatever the definition employed, the crucial fact is that the level of solvency constitutes a decision variable for the bank. It is confronted with refinancing cost according to the rate of interest it has to pay on its deposits $r_{D}$, which depends negatively on the bank's solvency level $S^{B}$. This enables the bank to obtain funds at a lower cost (see e.g., Aymanns et al. (2016) for empirical evidence).

$$
r_{D}=r_{D}(\cdot . S) \text {, with } \frac{\partial}{\partial S} r_{D}\left(. S^{B}\right)>0 \text { and } \frac{\partial^{2}}{\partial S^{B 2}} r_{D}\left(\cdot . S^{B}\right)>0 ;
$$

The arguments other than $S^{B}$ are discussed in Section 4.1 below. The amount of riskadjusted capital ${ }^{1} C>0$ increases with the targeted solvency level $S^{B}$ and $\alpha$, the parameter reflecting the regulatory capital requirements,

$$
\begin{gathered}
C=C\left(\cdot, S^{B} ; \alpha\right), \text { with } \frac{\partial}{\partial S^{B}} C\left(\cdot, S^{B}\right)>0, \frac{\partial^{2} C}{\partial S^{B 2}}>0 ; \\
\frac{\partial}{\partial \alpha} C\left(\cdot, S^{B}\right)=1 \text { for simplicity. }
\end{gathered}
$$

Note that for a given amount of deposits, $\alpha$ determines the bank's leverage ratio.

The rate of return $R^{B}$ is defined as the Division's net profit relative to the risk-adjusted capital invested at the beginning of the period (for simplicity of notation, this difference in time is neglected). Profit consists of two components. The first is net investment income $(\bar{\mu}-r) D$, where $\bar{\mu}$ denotes the rate of return on the capital market and $D$ denotes deposits. The second is the income $r_{G} C$ derived from the investing solvency capital; here, the rate $r_{G}$ reflects the fact that these funds must mainly be invested in guilt-edged securities, usually government bonds. Thus,

$$
R^{B}=\frac{\left(\bar{\mu}-r_{D}\left(\cdot, S^{B}\right)\right) D+r_{G} C\left(\cdot, S^{B} ; \alpha\right)}{C\left(\cdot, S^{B} ; \alpha\right)} .
$$

Moreover, the volume of the business portfolio, and hence $D$, is kept constant during the three (rather short) periods distinguished in Sections 6-8. Thus, maximization of $R^{B}$ in period 0 satisfies the following first-order condition for optimal solvency ${ }^{2}$.

$$
-\frac{\partial r_{D}\left[S^{B} * ; \alpha\right]}{\partial S^{B}}-\frac{\bar{\mu}-r_{D}\left[\cdot, S^{B} *\right]}{C\left[\cdot, S^{B} * ; \alpha\right]} \cdot \frac{\partial C\left[\cdot, S^{B} * ; \alpha\right]}{\partial S^{B}}=0
$$

Condition (4) states that the Division needs to weigh the decreased cost of refinancing (indicated by the first term) against the marginal cost of solvency, which consists of two interacting components. Solvency ties costly capital $C$ (as indicated by $\partial C\left[\cdot, S^{B} * ; \alpha\right] / \partial S^{B}$ ), a cost that is particularly high when the rate of return achievable $\bar{\mu}$ on the capital market far exceeds the bank's refinancing cost $r_{D}$ (see the term, $\bar{\mu}-r_{D}\left[\cdot, S^{B} *\right] / C\left[\cdot, S^{B} * ; \alpha\right]$ ). Note that an interior solution requires $\bar{\mu}>r_{D}$ (which is intuitive) because of $\partial r_{D} / \partial S^{B}<0$ (the rate of interest that has to be paid on deposits is lower when the level of solvency is high).

However, the terms $\partial r_{D} / \partial S^{B}$ and $\partial C / \partial S^{B}$ also depend on the changing conditions on the capital market reflected by exogenous shocks $d \bar{\mu}$ and $d \bar{\sigma}$, respectively (see assumptions Ba6 and Ba7 of Table A1 in Appendix A). Solvency regulation that neglects these dependencies may well create perverse incentives, as will become clear in Section 7. As an instance of such perverse incentives, there is historical evidence suggesting that banks used to have higher solvency levels before the imposition of solvency regulation than those prescribed even by Basel III. Adjusting for hidden reserves, Billings and Capie (2007) arrive at true capital-asset ratios as high as 8.12 percent in 1959-1967, among the five major UK banks. In comparison, Basel III mandates a (risk-weighted) common equity-asset ratio of 8 percent, which is equivalent to a capital-asset ratio of roughly 4 percent. This finding gives rise to the suspicion that banks may be induced to take on more rather than less risk due to regulation of the Basel type, a suspicion that will be confirmed in Section 7 below. 


\subsection{The Insurer's Investment and Underwriting Division Selects the Optimal Solvency Level}

For simplicity, the two main activities of an insurance company, risk underwriting and capital investment, are amalgamated into a single division (the Division henceforth). Thus, as in the case of a bank, let the Division maximize the risk-adjusted rate of return on capital $\left(R^{I}\right)$ through its choice of solvency $S^{I}$, acting in a risk-neutral manner. A higher level of solvency enables the company (and hence the Division) to obtain more funds through a higher premium income $P$ (for evidence, see e.g., Cummins and Sommer 1996; Epermanis and Harrington 2006).

Assuming decreasing marginal returns as usual, one has

$$
P=P\left(\cdot, S^{I}\right), \text { with } \frac{\partial}{\partial S^{I}} P\left(\cdot, S^{I}\right)>0 \text { and } \frac{\partial^{2}}{\partial S^{I 2}} P\left(\cdot, S^{I}\right)<0 ;
$$

the arguments other than $S^{I}$ are discussed in Section 4.1 below. The amount of solvency capital $^{3} C>0$ increases with the targeted solvency level $S^{I}$ and $\alpha$, the parameter reflecting the regulatory capital requirements,

$$
\frac{\partial}{\partial S^{I}} C\left(\cdot, S^{I} ; \alpha\right)>0, \frac{\partial^{2} C\left(\cdot, S^{I} ; \alpha\right)}{\partial S^{I 2}}>0 ; \frac{\partial}{\partial \alpha} C\left(\cdot, S^{I} ; \alpha\right)=1 \text { for simplicity. }
$$

The risk-adjusted rate of return $R^{I}$ depends on profits from capital investment and risk underwriting. As for profits from investment activity, they have two components. The first is denoted by $r_{G} C$ in Equation (7) below. Solvency capital $C$ (which is equated to capital for simplicity) must predominantly be invested in guild-edged securities (mainly government bonds) at a rate of return $r_{G}$. Note that this is not a risk-free interest rate; accordingly, there is no capital market line complementing the efficiency frontier depicted in Figure 1 (see Section 5 below). ${ }^{4}$ The second component is $k \bar{\mu} \cdot P\left(\cdot, S^{I}\right)$, i.e., premium income carried over from the previous period (the time difference is neglected for simplicity) which is not yet matched by insurance claims ${ }^{5}$. This makes funds available for investment according to the so-called funds-generating factor $k$ (Cummins and Phillips 2001). The higher $k$, the longer the lag between premiums received and claims paid. These funds can be invested at the rate of return $\bar{\mu}$ prevailing in the capital market.

The insurer also derives profit from risk underwriting, which is simply given by the difference between premium income $P\left(\cdot, S^{I}\right)$ and losses paid $L$. Assuming $L$ to be exogenous and abstracting from operating costs and taxes, $R^{I}$ can, therefore, be expressed as follows,

$$
R^{I}=\frac{r_{G} \cdot C\left(\cdot, S^{I}, \alpha\right)+k \bar{\mu} \cdot P\left(\cdot, S^{I}\right)+P\left(\cdot, S^{I}\right)-L}{C\left(\cdot, S^{I} ; \alpha\right)}=r_{G}+\frac{(1+k \bar{\mu}) P\left(\cdot, S^{I}\right)-L}{C\left(\cdot, S^{I} ; \alpha\right)} ;
$$

for the factors affecting $P$ and $C$ apart from $S^{I}$, see Table A1 of Appendix A.

Maximization of $R^{I}$ w.r.t. solvency $S^{I}$ leads to the first-order condition (8) for optimal solvency. Here, $e\left(P, S^{I}\right):=\left(\partial P / \partial S^{I}\right)\left(S^{I} / P\right)>0, e(P, C):=(\partial P / \partial C)(C / P)>0$ denote the elasticity of premium income and solvency capital w.r.t. the solvency level, respectively:

$$
\begin{gathered}
\frac{d R^{I}}{d S^{I}}=\frac{(1+k \bar{\mu})\left[\partial P / \partial S^{I} \cdot C-(P-L) \cdot \partial C / \partial S^{I}\right]}{C^{2}}=0, \text { hence } \\
\frac{d R^{I}}{d S^{I}}=\partial P / \partial S^{I} \cdot \frac{S^{I}}{P}-P \cdot \partial C / \partial S^{I} \frac{S^{I}}{C \cdot P}+L \cdot \partial C / \partial S^{I} \frac{S^{I}}{C \cdot P} \\
=e\left(P, S^{I}\right)-e\left(C, S^{I}\right)(1-L / P)=0 .
\end{gathered}
$$

after multiplication by $S^{I} / P>0$. Following Equations (7) and (8), $e\left(P, S^{I}\right)>0$; since $L / P<1$ under normal circumstances, boundary solutions $\left(S^{I *}=0\right.$ in particular) can be neglected.

Equation (8) can be interpreted as follows. The first term $e\left(P, S^{I}\right)>0$ represents the marginal benefit of increased solvency. It is balanced against its marginal cost by the Division, which is given by $e\left(C, S^{I}\right)>0$ reflecting the capital needed for a higher 
solvency level. This extra capital is weighted by $(1-L / P)$, the contribution to profit that an additional volume of underwriting would make.

However, the terms $e\left(P, S^{I}\right)$ and $e\left(C, S^{I}\right)$ depend not only on solvency $S^{I}$ but vary with the changing conditions on the capital market reflected by exogenous shocks $d \bar{\mu}$ and $d \bar{\sigma}$, respectively (see assumptions In6 and In7 of Table A1 in Appendix A). Once again, solvency regulation that fails to reflect this variability runs the risk of creating perverse incentives, as will become clear in Section 7.

\section{The Division Adjusts Solvency to Exogenous Shocks (Period 1) \\ 4.1. Adjustment by Banks}

Let there be changes in the rates of return $(d \bar{\mu})$ and volatility of returns $(d \bar{\sigma})$ occurring in the capital market. Being exogenous to the bank, they call for an adjustment of solvency if the Division is to maintain its optimal level, as prescribed by Equation (4).

As shown in Equation (A3) of Appendix B.1, optimal adjustment to a shock $d \bar{\mu}>0$ is given by (with $H^{B}:=\partial^{2} R^{B} / \partial S^{B 2}<0$ for the second-order condition, assumed to be satisfied):

$$
\begin{aligned}
& \frac{d S^{B} *}{d \bar{\mu}}=\underset{(-)}{\frac{-1}{H^{B}}}\left[\frac{\partial^{2} R^{B}}{\partial S^{B} \partial \bar{\mu}}\right] \\
& \left.\propto-\frac{\partial^{2} r_{D}}{\partial S^{B} \partial \bar{\mu}}+\frac{1}{\bar{\mu}-r_{D}}\left(\begin{array}{c}
1-\frac{\partial r_{D}}{\partial \bar{\mu}} \\
(+)
\end{array}\right) \begin{array}{c}
\frac{\partial r_{D}}{\partial S^{B}}-\frac{1}{C} \cdot \frac{\partial C}{\partial \bar{\mu}} \cdot \frac{\partial r_{D}}{\partial S^{B}}-\frac{\bar{\mu}-r_{D}}{C} \\
(+)
\end{array}\right) \frac{\partial^{2} C}{\partial S^{B} \partial \bar{\mu}} ;
\end{aligned}
$$

The terms are signed using assumptions $\mathrm{Ba} 2, \mathrm{Ba} 4, \mathrm{Ba} 6$, and $\mathrm{Ba} 8$ listed in Appendix A. Therefore, whether the solvency level increases or decreases in response to higher expected returns depends on four factors:

- The extent to which the (negative) effect of an increase in returns on the capital market $\bar{\mu}$ (which makes a positive value of the bank more likely) on the rate of interest that must be paid on deposits $r_{D}{ }^{6}$ is strengthened by a higher solvency level $S^{B}$, as indicated by $\partial^{2} r_{D} / \partial S^{B} \partial \bar{\mu}=\partial^{2} r_{D} / \partial \bar{\mu} \partial S^{B}<0$;

- $\quad$ The extent to which the rate of interest that must be paid on deposits $r_{D}$ decreases in response to a higher level of solvency $S^{B 7}$, somewhat conditioned by the increase in that rate in response to an increase in returns on the capital market $\bar{\mu}$ and is diminished by a large difference between that rate and returns achievable on the capital market, as indicated by $\left(1 / \bar{\mu}-r_{D}\right)\left(1-\partial r_{D} / \partial \bar{\mu}\right)\left(\partial r_{D} / \partial S^{B}\right)<0$;

- The extent to which the rate of interest that must be paid on deposits $r_{D}$ decreases in response to a higher level of solvency $S^{B}$, conditioned by the fact that an increase in expected returns $\bar{\mu}$ on the capital market makes a positive value of the bank more likely, so it reduces the need for solvency capital, resulting in less additional solvency capital relative to its initial value, as indicated by $(1 / C)(\partial C / \partial \bar{\mu})\left(\partial r_{D} / \partial S^{B}\right)>0$;

- The extent to which the need for additional solvency capital $C$ for a higher level of solvency $S^{B}$ is reduced due to higher expected returns $\bar{\mu}$ on the capital market (which makes a positive value of the bank more likely), relative to the initial value of $C$, magnified by the difference between achievable returns and the rate of interest that must be paid for deposits, as indicated by the last term, $\left(\bar{\mu}-r_{D}\right)(1 / C)\left(\partial^{2} C / \partial S^{B} \partial \bar{\mu}\right)=$ $\left(\bar{\mu}-r_{D}\right)(1 / C)\left(\partial^{2} C / \partial \bar{\mu} \partial S^{B}\right)$.

In principle, a change $d \bar{\mu}$ also affects $H^{B}$ ( $H^{I}$, respectively, see Section 4.2). However, this impact must be minor lest there is a sign change, which would transform a maximum into a minimum. Therefore, $H^{B}\left(H^{I}\right.$, respectively) is treated as a constant w.r.t. $\bar{\mu}$ (as well as $\bar{\sigma}$, see below). In view of assumption Ba4, which states that the multiplier $\left(1-\partial r_{D} / \partial \bar{\mu}\right)$ is bounded by $(0,1)$, Equation (9) yields: 


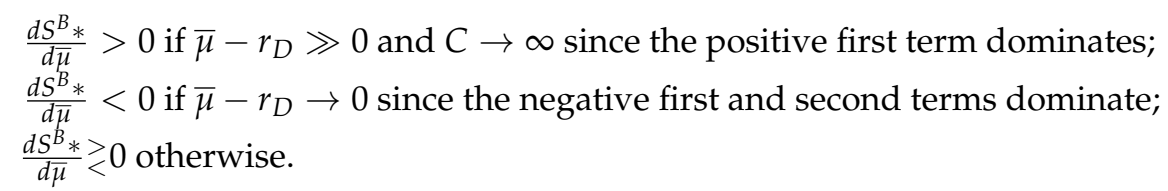

If and when the margin $\bar{\mu}-r_{D}$ should become large again while ample capital is available, a change $d \bar{\mu}>0$ facilitates the attainment of a higher solvency level. However, if the margin is extremely small, the Division is predicted to lower the level of solvency in response to an exogenous increase in expected returns, since it needs to preserve costly capital. This prediction is relevant for the near-zero interest rate environment prevailing since 2007.

Now consider a shock $d \bar{\sigma}>0$ (see Equation (A5) in Appendix B.1),

$$
\begin{aligned}
& \frac{d S^{B} *}{d \bar{\sigma}} \propto \frac{\partial^{2} R^{B}}{\partial S^{B} \partial \bar{\sigma}} \\
& =-\frac{\partial^{2} r_{D}}{\partial S^{B} \partial \bar{\sigma}}-\frac{1}{\bar{\mu}-r_{D}} \cdot \frac{\partial r_{D}}{\partial \bar{\sigma}} \cdot \frac{\partial r_{D}}{\partial S^{B}}-\frac{1}{C} \cdot \frac{d C}{d \bar{\sigma}} \cdot \frac{\partial r_{D}}{\partial S^{B}}-\frac{\bar{\mu}-r_{D}}{C} \cdot \frac{\partial^{2} C}{\partial S^{B} \partial \bar{\sigma}^{\prime}},
\end{aligned}
$$

with the signs reflecting assumptions $\mathrm{Ba} 3, \mathrm{Ba} 5, \mathrm{Ba} 7$, and $\mathrm{Ba}$. Whether the solvency level increases or decreases in response to higher volatility on the capital market again depends on four factors:

- The extent to which the (positive) effect of an increase in volatility on the capital market $\bar{\sigma}$ on the rate of interest that must be paid on deposits $r_{D}{ }^{8}$ is mitigated by a higher solvency level $S^{B}$, as indicated by $\partial^{2} r_{D} / \partial S^{B} \partial \bar{\sigma}=\partial^{2} r_{D} / \partial \bar{\sigma} \partial S^{B}<0$;

- The extent to which the rate of interest that must be paid on deposits $r_{D}$ decreases in response to a higher level of solvency $S^{B}$, magnified by the increase in that rate in response to an increase in volatility on the capital market $\bar{\sigma}$, and is diminished by a large difference between that rate and returns achievable on the capital market, as indicated by $\left(1 / \bar{\mu}-r_{D}\right)\left(\partial r_{D} / \partial \bar{\sigma}\right)\left(\partial r_{D} / \partial S^{B}\right)>0$;

- The extent to which the rate of interest that must be paid on deposits $r_{D}$ decreases in response to a higher level of solvency $S^{B}$, conditioned by the fact that an increase in expected returns $\bar{\mu}$ on the capital market makes a positive value of the bank more likely, so it reduces the need for additional solvency capital relative to its initial value, as indicated by $(1 / C)(\partial C / \partial \bar{\mu})\left(\partial r_{D} / \partial S^{B}\right)<0$;

- $\quad$ The extent to which the need for additional solvency capital $C$ for a higher level of solvency $S^{B}$ is reduced due to higher expected returns $\bar{\mu}$ on the capital market, which makes a positive value of the bank more likely, relative to the initial value of $C$, magnified by the difference between achievable returns and the rate of interest that must be paid for deposits, as indicated by $\left(\bar{\mu}-r_{D}\right)(1 / C)\left(\partial^{2} C / \partial S^{B} \partial \bar{\mu}>0\right.$.

In view of Equation (11), one obtains

$$
\begin{aligned}
& \frac{d S^{B} *}{d \bar{\sigma}}>0 \text { if } \bar{\mu}-r_{D} \rightarrow 0 \text { or if } C \rightarrow \infty \\
& \text { since the positive first three terms dominate; } \\
& \frac{d S^{B} *}{d \bar{\sigma}} \gtrless 0 \text { otherwise. }
\end{aligned}
$$

When volatility of returns on the capital market increases, the bank can refinance itself at a lower interest rate paid on deposits, an effect that is reinforced when its solvency level is high. If in addition ample solvency capital reduces the opportunity cost of solvency (see Equation (4) again), it is appropriate for the Division to increase the solvency level.

\subsection{Adjustment by Insurers}

Exogenous changes in rates of return $(d \bar{\mu})$ and volatility of returns $(d \bar{\sigma})$ are again assumed to occur. To derive the optimal adjustments of the solvency level, the assumptions In2, In4, In6, and In8 listed in Table A1 of Appendix A are introduced. In the case of 
$d \bar{\mu}>0$, this is given by (see Equation (A7) of Appendix B.2), with $H^{I}:=\partial^{2} R / \partial S^{2}<0$ as the second-order condition),

$$
\begin{aligned}
& \frac{d S^{I} *}{d \bar{\mu}}=\frac{-1}{H^{I}} \cdot \frac{\partial^{2} R^{I}}{\partial S^{I} \partial \bar{\mu}} \propto S^{I} \times \\
& \left\{\begin{array}{c}
\frac{\partial^{2} P}{\partial S^{I} \partial \bar{\mu}} \cdot \frac{1}{P}-\frac{\partial P}{\partial S^{I}} \cdot \frac{\partial P / \partial \bar{\mu}}{P^{2}}-\left[\begin{array}{cc}
\frac{\partial^{2} C}{\partial S^{I} \partial \bar{\mu}} \\
(+)
\end{array}\left(\begin{array}{cc}
C \\
(+)
\end{array}\right) \begin{array}{l}
\frac{\partial C}{\partial S^{I}} \cdot \frac{\partial C / \partial \bar{\mu}}{C^{2}} \\
(+)
\end{array}\right)(1-L / P)+\frac{\partial C}{\partial S^{I}} \cdot \frac{L \cdot \partial P / \partial \bar{\mu}}{C \cdot P^{2}} \\
(+)
\end{array} \begin{array}{c}
(+) \\
(+)
\end{array}\right\} .
\end{aligned}
$$

Therefore, whether the company increases or lowers its solvency level depends on five factors, each magnified by a high initial level:

- The extent to which the negative relationship between expected returns on the capital market $\bar{\mu}$ and premium income $P$ is mitigated by a higher solvency level, conditioned by the initial value of premiums, as indicated by $\left(\partial^{2} P / \partial S^{I} \partial \bar{\mu}\right)(1 / P)=$ $\left(\partial^{2} P / \partial \bar{\mu} \partial S^{I}\right)(1 / P)>0$;

- The extent to which the negative relationship between expected returns on the capital market $\bar{\mu}$ and premium income $P$ is neutralized by the positive impact of solvency on premium income $\partial P / \partial S$, strongly conditioned by its initial value, as indicated by $-\left(\partial P / \partial S^{I}\right) \cdot(\partial P / \partial \bar{\mu})\left(1 / P^{2}\right)>0$;

- The extent to which the reduced need for solvency capital $C$ thanks to high expected returns on the capital market $\bar{\mu}$ is reinforced by a high solvency level, conditioned by the initial value of capital and the amount of premium income available for investment indicated by $-\left(\partial^{2} C / \partial S^{I} \partial \bar{\mu}\right)(1 / C)(1-L / P)=-\left(\partial^{2} C / \partial \bar{\mu} \partial S^{I}\right)(1 / C)(1-L / P)>0$;

- The extent to which the need for solvency capital $C$ is reduced thanks to high expected returns on the capital market $\bar{\mu}$, combined with the positive relationship between the solvency level to be attained and the solvency capital, conditioned by the initial value of the capital (strongly) and the amount of premium income available for investment, as indicated by $\left(\partial C / \partial S^{I}\right)(\partial C / \partial \bar{\mu})\left(1 / C^{2}\right)(1-L / P)>0$;

- The extent to which the negative relationship between premium income $P$ and expected returns on the capital market $\bar{\mu}$ is magnified by losses $L$ but is conditioned by a high initial value of solvency capital as well as (strongly) the amount of premium income $P$, in conjunction with the need for additional capital for attaining a higher degree of solvency, as indicated by $-\left(\partial C / \partial S^{I}\right)(L)(\partial P / \partial \bar{\mu})\left(1 / C \cdot P^{2}\right)<0$.

In view of Equation (13), one obtains, with focus again on the amount of solvency capital as in the case of banks,

$$
\frac{d S^{I} *}{d \bar{\mu}} \rightarrow 0 \text { if } S^{I} \rightarrow 0
$$

$\frac{d S^{I} *}{d \bar{\mu}}>0$ if the first positive term in the bracket is not dominated by the negative ones, i.e., if $\rightarrow 0$;

$\frac{d S^{I} *}{d \bar{\mu}}<0$ if $C \rightarrow 0$ since $1 / C^{2} \rightarrow \infty$ faster than $1 / C \rightarrow \infty$, causing the negative second

and fourth terms in the bracket to dominate;

$\frac{d S^{I} *}{d \bar{\mu}} \gtrless 0$ otherwise.

These results are intuitive because the optimal adjustment of the solvency level to a change in the rate of return on the capital market is proportional to its current value $S^{I}$, it goes to zero if this value is very low to begin with. With a large solvency capital, the opportunity cost of an increase in $S^{I}$ is small (see the second line of Equation (8)), leading the Division to increase $S^{I}$ with the aim of boosting premium income. Since most insurers have excessive solvency capital (Nakada et al. 1999), this is considered to be the 
normal response. In the case of a very small capital base $C$, however, preserving it for the underwriting business argues in favor of decreasing the solvency level $S^{I}$.

Turning to a shock $d \bar{\sigma}>0$ and using the assumptions $\operatorname{In} 3, \operatorname{In} 5, \operatorname{In} 7$, and In 9 listed in Table A1 of Appendix A, one obtains from Equation (A8) of Appendix B.2,

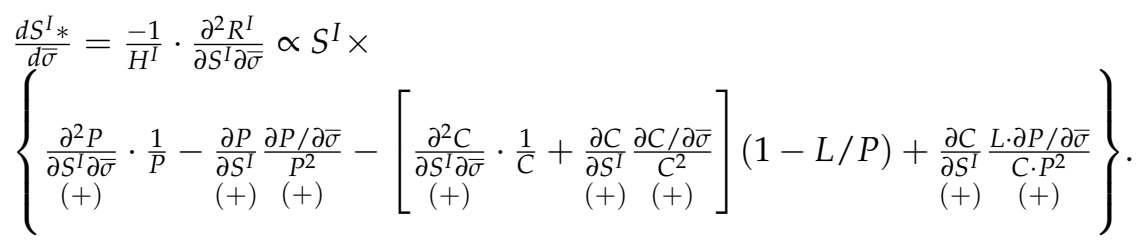

Therefore, whether the company increases or lowers its solvency level depends on five factors, each magnified by a high initial level:

- The extent to which the positive relationship between volatility of returns on the capital market $\bar{\sigma}$ and premium income $P$ is reinforced by a higher solvency level, conditioned by the initial value of premiums, is indicated by $\left(\partial^{2} P / \partial S^{I} \partial \bar{\sigma}\right)(1 / P)=$ $\left(\partial^{2} P / \partial \bar{\sigma} \partial S^{I}\right)(1 / P)>0$.

- $\quad$ The extent to which the positive relationship between expected returns on the capital market $\bar{\sigma}$ and premium income $P$ combines with the positive impact of solvency on premium income $\partial P / \partial S^{I}$, strongly conditioned by its initial value, is indicated by $-\left(\partial P / \partial S^{I}\right) \cdot(\partial P / \partial \bar{\sigma})\left(1 / P^{2}\right)<0$.

- The extent to which the increased need for solvency capital $C$ due to high volatility of returns on the capital market $\bar{\sigma}$ is reinforced by a targeted high solvency level, conditioned by the initial value of capital and the amount of premium income available for investment, is indicated by $-\left(\partial^{2} C / \partial S^{I} \partial \bar{\sigma}\right)(1 / C)(1-L / P)=$ $-\left(\partial^{2} C / \partial \bar{\sigma} \partial S^{I}\right)(1 / C)(1-L / P)<0$.

- The extent to which the increased need for solvency capital $C$ due to high volatility of returns on the capital market $\bar{\sigma}$ combines with the positive relationship between the solvency level to be attained and solvency capital, conditioned by the initial value of capital (strongly) and the amount of premium income available for investment, is indicated by $-\left(\partial C / \partial S^{I}\right)(\partial C / \partial \bar{\mu})\left(1 / C^{2}\right)(1-L / P)<0$.

- The extent to which the positive relationship between premium income $P$ and volatility of returns on the capital market $\bar{\sigma}$ is magnified by losses $L$ but conditioned by a high initial value of the solvency capital, as well as (strongly) the amount of premium income $P$ in conjunction with the need for additional capital for attaining a higher degree of solvency, is indicated by $\left(\partial C / \partial S^{I}\right)(L)(\partial P / \partial \bar{\sigma})\left(1 / C \cdot P^{2}\right)>0$.

Equation (15) implies

$$
\begin{aligned}
& \frac{d S^{I} *}{d \bar{T}} \rightarrow 0 \quad \text { if } S^{I} \rightarrow 0 \text {; } \\
& \frac{d S^{I} *}{d \bar{\sigma}}>0 \quad \text { if the positive first and fourth terms are not dominated by the negative } \\
& \text { ones, i.e. if } C \rightarrow \infty \text { (and } P \text { large, noting that } 1 / P^{2} \rightarrow 0 \text { faster than } \\
& 1 / P \rightarrow 0 \text { when } P \rightarrow \infty) \text {; } \\
& \frac{d S^{I} *}{d \bar{\sigma}}<0 \quad \text { if } C \rightarrow 0 \text {, since } 1 / C^{2} \rightarrow \infty \text { faster than } 1 / C \rightarrow \infty \text {, causing the } \\
& \frac{d S^{I} *}{d \bar{\sigma}} \quad \begin{array}{ll}
\geq 0 \text { otherwise } \\
\end{array}
\end{aligned}
$$

As will be argued below in Equation (18), $d S^{I} * / d \bar{\sigma}>0$ can be considered the normal response.

\section{The Division Derives an Endogenous Perceived Efficiency Frontier (Period 2)}

\subsection{The Endogenous Perceived Efficiency Frontier (EPEF) of the Bank}

In the second period, the bank inherits a net adjustment of solvency $d S^{B} *$ that is the result of responses to the shocks $(d \bar{\mu}, d \bar{\sigma})$ that occurred in the first period. Being 
predetermined, the change $d S^{B} *$ now acts like an exogenous shock. By dividing Equation (11) by Equation (9), one obtains Equation (17) below, which indicates the slope $d \hat{\mu} / d \hat{\sigma}$ of the bank's perceived endogenous efficiency frontier (EPEF). The EPEF is created by the Division, who performs adjustments $(d \bar{\mu}, d \bar{\sigma})$ by reshuffling the bank's assets.

$$
\begin{aligned}
& \left.\frac{d \hat{\mu}}{d \hat{\sigma}}\right|_{S *} ^{B}=\frac{-\frac{\partial^{2} r_{D}}{\partial S^{B} \partial \bar{\sigma}}-\frac{1}{\bar{\mu}-r_{D}} \cdot \frac{\partial r_{D}}{\partial \bar{\sigma}} \cdot \frac{\partial r_{D}}{\partial S^{B}}-\frac{1}{C} \cdot \frac{\partial C}{\partial \bar{\sigma}} \cdot \frac{\partial r_{D}}{\partial S^{B}}-\frac{\bar{\mu}-r_{D}}{C} \cdot \frac{\partial^{2} C}{\partial S^{B} \partial \bar{\sigma}}}{-\frac{\partial^{2} r_{D}}{\partial S \partial \bar{\mu}}+\frac{1}{\bar{\mu}-r_{D}}\left(\begin{array}{c}
\left.1-\frac{\partial r_{D}}{\partial \bar{\mu}}\right) \\
(+)
\end{array}\right) \frac{\partial r_{D}}{\partial S^{B}}-\frac{1}{C} \cdot \frac{\partial C}{\partial \bar{\mu}} \cdot \frac{\partial r_{D}}{\partial S^{B}}-\frac{\bar{\mu}-r_{D}}{C} \cdot \frac{\partial^{2} C}{\partial S^{B} \partial \bar{\mu}}} \\
& >0 \text { if } C \gg 0 \text { and } \bar{\mu}-r_{D} \gg 0 \text { since accordingto Equations (10) and (12), } \\
& \text { both numerator and denominator are positive; } \\
& <0 \text { possible especially if } \bar{\mu}-r_{D} \rightarrow 0 \text { since according to Equation (10), } \\
& \text { the denominator is negative while according to Equation (12), } \\
& \text { the sign of the numerator isindeterminate in thi scase. }
\end{aligned}
$$

Therefore, the slope of the EPEF is not necessarily positive, contrary to capital market theory and usual market experience. It can be negative in particular when the margin $\bar{\mu}-r_{D}$ is very small, as in the situation created by Quantitative Easing since 2007 (see segments of the EPEF with negative slope, dashed in Figure 1). A crucial result to be noted already at this point is that the slope defined in Equation (17) depends not only on easily observable quantities $\left(C, S^{B}\right)$ and first-order effects such as $\left(\partial r_{D} / \partial \bar{\mu}, \partial r_{D} / \partial \bar{\sigma}\right)$ but also the terms $\left(\partial^{2} C / \partial S^{B} \partial \bar{\mu}, \partial^{2} C / \partial S^{B} \partial \bar{\sigma}\right)$, which indicate that the relationship between capital required and solvency varies with conditions on the capital market (see in particular assumptions Ba8 and Ba9 in Table A1 again).

Figure 1 shows three EPEFs (minimum variance points are not shown to preserve space $)^{9}$. Note that $\bar{\mu}$ and $\hat{\mu}$ as well as $\bar{\sigma}$ and $\hat{\sigma}$ are depicted on the same axis. This reflects the assumption that e.g., a low first-period value of $\bar{\sigma}$ tends to translate into a low optimal $\sigma^{*}$. The first EPEF (labeled $S^{*}$ ) holds prior to the influence of regulation. The two other frontiers (labelled Basel I, II and Basel III, $d \alpha>0$ ) are modified by Basel I, II, and III (Solvency I, II, and planned Solvency III, respectively) regulation in ways to be discussed in Sections 6-8 below.

\subsection{The Endogenous Perceived Efficiency Frontier (EPEF) of the Insurer}

For the slope of the insurer's EPEF, division of Equation (15) by Equation (13) yields

$$
\begin{aligned}
& \left.\frac{d \hat{\mu}}{d \hat{\sigma}}\right|_{S *} ^{I}=
\end{aligned}
$$

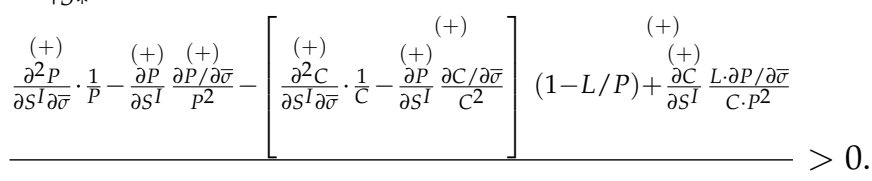

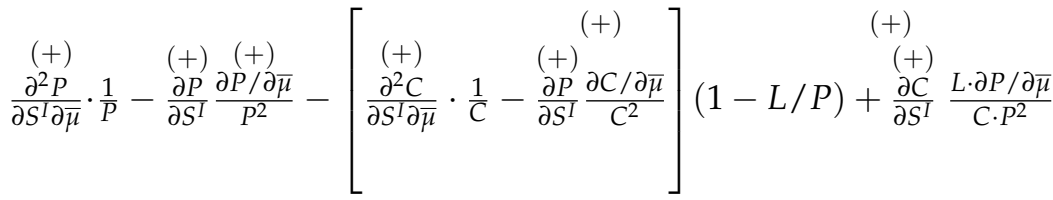

In principle, Equation (18) is of indeterminate sign, even if normally its denominator is positive (see the comment below Equation (13)). However, daily experience of investors in the capital market suggests that the slope of the efficiency frontier in $(\hat{\mu}, \hat{\sigma})$-space is positive. With the denominator positive, the numerator must also be positive (this is of importance in Section 7.2 below). Once again, the slope of the EPEF depends not only on easily observable quantities $\left(C, P, S^{I}\right)$ and first-order effects such as $(\partial P / \partial \bar{\mu}, \partial P / \partial \bar{\sigma})$. Rather, it is also determined by terms such as $\left(\partial^{2} P / \partial S^{I} \partial \bar{\mu}, \partial^{2} P / \partial S^{I} \partial \bar{\sigma}\right)$ indicating that the 
relationship between premium income and solvency varies with the conditions of the capital market (see in particular assumptions In8 and In9 in Table A1).

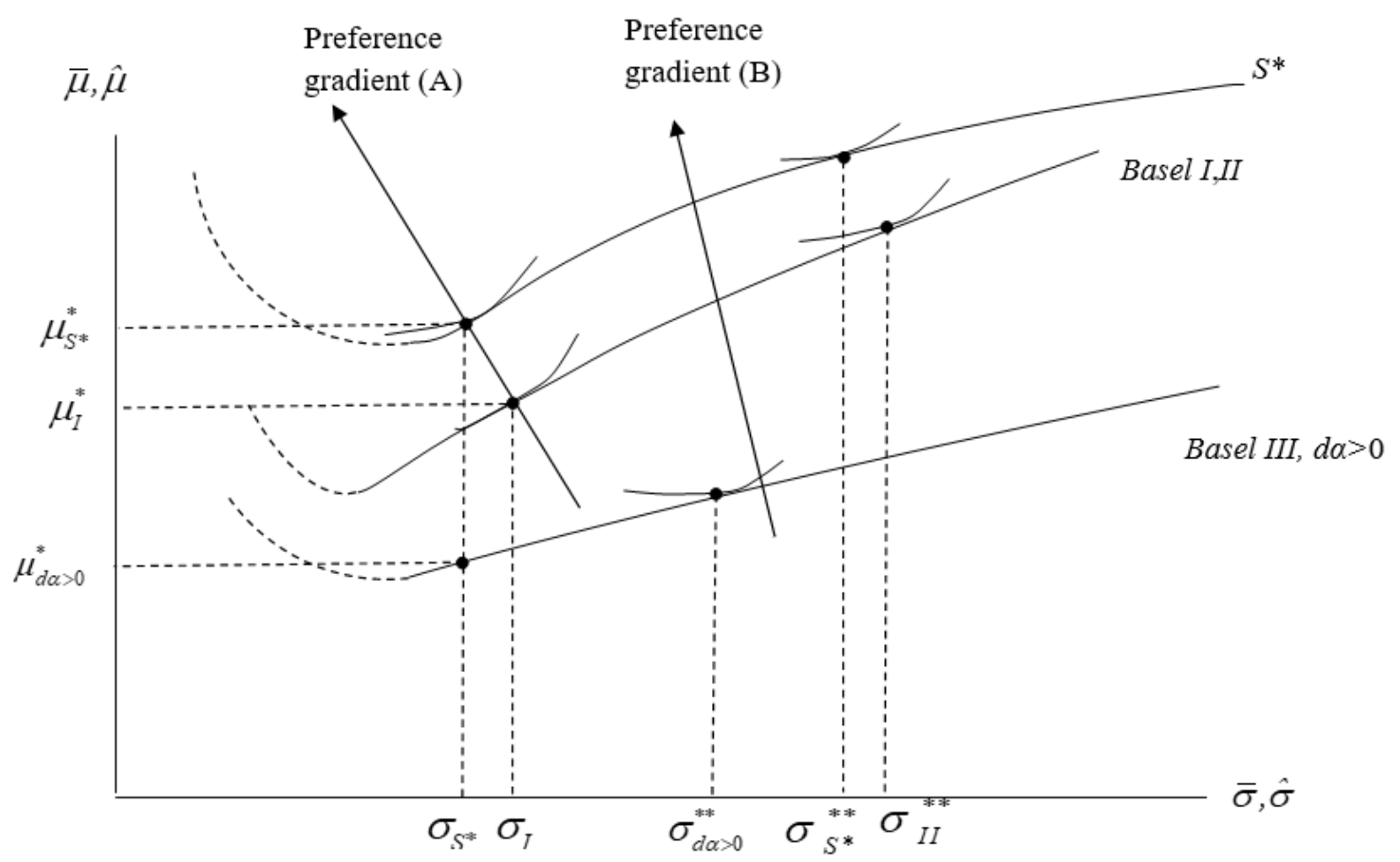

Figure 1. Endogenous perceived efficiency frontiers in $(\hat{\mu}, \hat{\sigma})$-space.

\section{Senior Management Opts for a Point on the EPEF (Period 3)}

In the third period, senior management selects the optimum point on the pertinent EPEF of Figure 1. Its risk appetite is reflected by two sets of indifference curves, with set $\mathrm{A}$ depicting strong risk aversion and set $\mathrm{B}$ showing weak risk aversion. For a senior management of type A, e.g., $\left(\mu_{S^{*}}^{*}, \sigma_{S^{*}}^{*}\right)$ reflects the optimal expected rate of return on capital, combined with the volatility of these returns prior to the imposition of solvency regulation ${ }^{10}$.

Note that in view of Equations (17) and (18), this optimum also depends on $\partial^{2} C / \partial S \partial \bar{\mu}$ and $\partial^{2} C / \partial S \partial \bar{\sigma}$, two parameters that indicate that the relationship between the solvency level and solvency capital is not fixed but depends on the state of the capital market (see assumptions Ba8 and Ba9 as well as In8 and In9 of Appendix A again). For banks, there is some historical evidence supporting this claim. According to Billings and Capie (2007), the capital-asset ratios of the five major UK banks reached a peak during 1942-1946, when they had to finance the war effort. Their explanation was "... that much of their lending to government was in the form of marketable securities, which have generated exposure to fluctuations in market prices" (p. 152, emphasis added). Banks apparently realized that changes in the relationship between solvency and risk capital occurred due to the changing market conditions during World War II, causing their EPEF to be modified.

\section{Solvency Regulation Affects the Perceived Endogenous Efficiency Frontier}

\subsection{Basel I and II}

In Figure 1, the EPEF labelled Basel I, II (see below) runs below the frontier labelled $S^{*}$ because public regulation can never increase a private actor's feasible set (this also holds also for Solvency I and II). In addition, it has a steeper slope, as will be shown in the next two paragraphs. As to senior management's risk preferences, homotheticity is assumed, in order to obtain unambiguous predictions. This stability assumption evidently 
is somewhat problematic in view of "irrational exuberance" (Shiller 2016), which can be interpreted as reflecting a reduced degree of risk aversion in a boom phase but a higher one in a downturn, with the two phases likely differing in terms of the $(\mu, \sigma)$-values chosen by financial institutions.

Basel I stipulated capital requirements as a function of risk-weighted assets and separately for off-balance sheet positions (Basel Committee on Banking Supervision 1988) ${ }^{11}$. By defining four asset classes with fixed weights, Basel I imposed a fixed relationship between solvency capital $C$ and solvency $S^{B}$. However, when (exogenous) rates of return on the capital market improve $(d \bar{\mu}>0)$, the bank needs less solvency capital to attain a given solvency level, while if volatility increases $(d \bar{\sigma}>0)$, it needs more capital to attain it (see assumptions Ba8 and Ba9 of Appendix A). In terms of the model, Basel I amounts to the following restrictions:

$$
\frac{\partial^{2} C}{\partial S^{B} \partial \bar{\mu}}=0, \frac{\partial^{2} C}{\partial S^{B} \partial \bar{\sigma}}=0 .
$$

In Equation (17), these restrictions cause the numerator to increase and the denominator to decrease, resulting in a steepening of the EPEF. Given homothetic risk preferences, the implication is unambiguous. Regardless of its degree of risk aversion, senior management is predicted to opt for more volatility (in the case of type $\mathrm{A}, \sigma_{I}^{*}$ rather than $\sigma_{S *}^{*}$ in Figure 1).

The innovation of Basel II was to allow a choice of approach for the calculation of capital requirements between the Standardized Approach and the Internal Ratings-Based Approach (Basel Committee on Banking Supervision 2004). Small banks continued to employ the Standardized Approach, which amounted to Basel I, while large ones mostly preferred the Internal Ratings-Based Approach, despite its higher cost of implementation in an attempt to save on capital. However, once a bank had adopted a particular internal model, it could not modify it anymore. Whenever $d \bar{\mu}<0$ or $d \bar{\sigma}>0$ on the capital market and the solvency requirement was binding, it had to increase its capital base. Since the rules promulgated by the Basel Committee on Banking Supervision (2014, especially paragraph 40-44) continued to establish a fixed relationship between a targeted solvency level and required risk capital, the restrictions in Equation (19) apply in this situation, causing the slope of the EPEF to increase again (see Zweifel et al. 2015 for more details; the fact that the EPEFs under Basel II and Basel I usually do not coincide is neglected in Figure 1 for simplicity). A bank with a senior management of type B is therefore predicted to opt for an increase in volatility, from $\sigma_{S *}^{* *}$ to $\sigma_{I I}^{* *}$, also under the influence of Basel II.

This unintended outcome may have been more common than envisaged. As stated by Benink and Benston (2005), "Although the CEOs and directors of banks may not deliberately hold an insufficiently high level of capital necessary to avoid insolvency, they may be lulled into believing that they are adequately capitalized if they adhere to the Basel Committee's models (which they are unlikely to understand" (p. 308).

Arguably a bank might neglect the restrictions stated in Equation (19). Yet responsibilityaverse managers (Power 2004) may use regulatory decision rules as a convenient justification of their actions. For example, let there be a second-period downward adjustment in solvency by the Division. Therefore, the bank should move in on its EPEF. With the flat endogenous efficiency frontier $S^{*}$ (Figure 1 in view), the Division would propose to accept a substantial decrease in volatility. However, in view of the steeper efficiency frontier induced by Basel I and II, the suggested decrease is smaller. If the bank's senior management were to move along $S^{*}$, it could be criticized by the shareholders for sacrificing excessive amount of returns. This threat may be sufficient for management to adopt the restrictions (19) and hence the EPEF modified by regulation.

One might also argue that an increase in volatility does not necessarily imply a decrease in solvency. As long as the EPEF has a positive slope, more volatility has the benefit of higher expected returns (see Figure 1). However, if one accepts the lognormal distribution of returns as an approximation, an increase of $\hat{\sigma}$ by $x$ percent would have to be associated with an increase in $\hat{\mu}$ by $x$ percent for $V a R$ and $E V a R$ to remain constant (in analogy to Cummins and Nye (1981)). This would call for the EPEF to have unitary 
elasticity, implying $(d \hat{\mu} / \hat{\mu}) /(d \hat{\sigma} / \hat{\sigma})=1$ and hence $d \hat{\mu} / d \hat{\sigma}=\hat{\mu} / \hat{\sigma}$. Now according to http: / / www.investopedia.com/articles/basics/09 (accessed 17 June 2020), $\mu=9.5$ percent and $\sigma=10$ percent p.a. for S\&P 500 stocks, up to 2009 . Therefore, $d \hat{\mu} / d \hat{\sigma} \geq 0.95$ would be necessary for ensuring constancy of $\mathrm{VaR}$ and $E V a R$. Yet much lower slopes (typically below 0.5) have been found in empirical research see e.g., Woehrmann et al. (2004). In sum, the predicted increase in $\hat{\sigma}$ does cause a reduction in solvency.

\subsection{Solvency I and II}

Capital requirements mandated by Solvency I reflect insurers' risk-weighted assets and off-balance sheet positions in the same way as Basel I regulation (Basel Committee on Banking Supervision 1988). Distinguishing four asset classes with fixed weights, it imposes a fixed relationship between solvency capital $C$ and solvency $S^{I}$. Insurers are prevented from reacting to changes in capital markets; in terms of the model, this neglect amounts to restrictions analogous to those stated in Equation (19). In Equation (18), these restrictions cause the numerator to increase and the denominator to decrease when $\partial^{2} C / \partial S^{I} \partial \bar{\mu}$ drops out. The result is a steepening of the EPEF, as in the case of banks.

Turning to Solvency II, insurance companies have a choice of approach for the calculation of capital requirements, viz. the Standardized Approach and the Internal Ratings-Based Approach, exactly as in Basel II (Basel Committee on Banking Supervision 2004) ${ }^{12}$. In sum, Solvency I and II regulation induces insurers to be less conservative, regardless of the degree of risk aversion (types A and B in Figure 1; see the movements from $\sigma^{*}{ }_{S *}$ to $\sigma^{*}{ }_{I}$ and from $\sigma^{* *} S_{*}$ to $\sigma^{* *}$, respectively).

\section{The New Regulation: Basel III and Planned Solvency III}

\subsection{Basel III}

Fearing that banks may still be exposed to excessive risk despite Basel II regulation, both the International Monetary Fund (International Monetary Fund 2013) and the European Central Bank (ECB) performed stress tests, subjecting banks to shocks notably originating in the capital market. Arguably, this constitutes indirect evidence in favor of the argument proffered in this paper, viz. that Basel I and II may have induced banks to take on more rather than less risk. The simulations undertaken by IMF and ECB motivated Basel III regulation to be fully implemented by 2027. Its objective is to enhance solvency by an increase in solvency capital, in particular equity (Basel Committee on Banking Supervision 2017).

Another innovation of Basel III regulation is that banks should take developments in the capital markets into due account, as stated in "Principle 3: The banks' risk appetite for IRRBB [Interest Rate Risk in the Banking Book] should be articulated in terms of the risk to both economic value and earnings. Banks must implement policy limits that target maintaining IRRBB exposures consistent with their risk appetite". Specifically, the Basel Committee on Banking Basel Committee on Banking Supervision (2016) states "Principle 5: In measuring IRRBB, key behavioral and modelling assumptions should be fully understood, conceptually sound and documented. Such assumptions should be rigorously tested and aligned with the bank's business strategies." Evidently, this mandates banks to develop best estimates of all parameters entering the determination of $d S^{B *} / d \bar{\mu}$ and $d S^{B *} / d \bar{\sigma}$ appearing in Equation (17), reflecting "the bank's business strategies". They can now determine their EPEF without any parameter restrictions of the type stated in Equation (19). In terms of Figure 1, Basel III re-establishes the original EPEF denoted by $S^{*}$ as the point of departure in principle (but see below).

Moreover, the implementation of the policy limits cited above can indeed be delegated to senior management according to "Principle 2: The governing body of each bank is responsible for oversight of the IRRBB management framework, and the bank's risk appetite for IRRBB. Monitoring and management of IRRBB may be delegated by the governing body to senior management, expert individuals or an asset and liability management committee ... " (Basel Committee on Banking Supervision 2016).

An important new element of Basel III is a limit on the banks' leverage ratio (Basel Committee on Banking Supervision 2014), which is equivalent to an increased capital 
requirement ceteris paribus. The effect of a higher capital requirement $(d \alpha>0)$ on the bank's EPEF can be determined as follows. First, it imposes another constraint on the banking business; accordingly, the EPEF labelled Basel III, $\mathrm{d} \alpha>0$ in Figure 1 runs, at least, as low as that labelled Basel I, II. However, it also reduces its slope. Let $N^{B}>0$ as the numerator and $\Delta^{\mathrm{B}}>0$ be the denominator of Equation (17) and consider its derivative w.r.t. to $\alpha$ (recalling that $\partial C / \partial \alpha=1$ in Equation (2)),

$$
\begin{aligned}
& \frac{\partial}{\partial \alpha}\left[\left.\frac{d \hat{\mu}}{d \hat{\sigma}}\right|_{S *} ^{B}\right]
\end{aligned}
$$

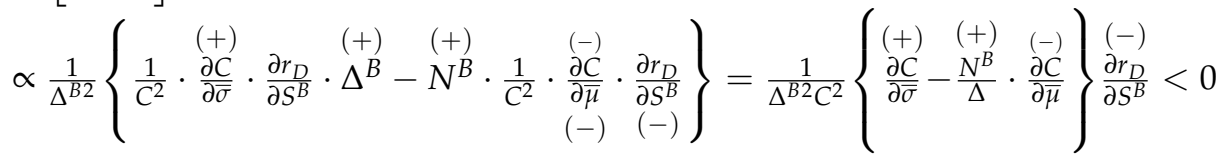

Therefore, the new solvency regulation causes the slope of the EPEF to decrease rather than increase, compared to the one labelled $S^{*}$. With the removal of the "deformation" caused by Basel I and II combined with the increase in required solvency capital, the Basel III regulation, thus, will induce banks to move to less volatile asset-liability positions (marked $\sigma_{d a>0}^{* *}$ in Figure 1 for a type B management), and hence, increase solvency, achieving its stated aim.

\subsection{Planned Solvency III}

If modelled after Basel III, planned Solvency III will also remove the restrictions stated in Equation (19), also making the EPEF labelled $S^{*}$ in Figure 1 the original one for insurers. A higher capital requirement can be shown to reduce its slope at least for some insurers. Let $N^{I}>0$ denote the numerator and $\Delta^{\mathrm{I}}>0$ the denominator of Equation (18), and consider its derivative w.r.t. to $\alpha$ (recalling again that $\partial C / \partial \alpha=1$ ),

$$
\begin{aligned}
& \frac{\partial}{\partial \alpha}\left[\left.\frac{d \hat{\mu}}{d \hat{\sigma}}\right|_{S *} ^{I}\right] \\
& \propto\left\{-\left[-\frac{\partial^{2} C}{\partial S^{I} \partial \bar{\sigma}} \cdot \frac{1}{C^{2}}-\frac{\partial P}{\partial S^{I}} \cdot \frac{-\partial C / \partial \bar{\sigma}}{C^{4}}\right](1-L / P)-\frac{\partial C}{\partial S^{I}} \cdot \frac{L \cdot \partial P / \partial \bar{\sigma}}{C^{2} \cdot P^{2}}\right\} \cdot \Delta^{I} \\
& -N^{I}\left\{\left[-\frac{\partial^{2} C}{\partial S^{I} \partial \bar{\mu}} \cdot \frac{1}{C^{2}}-\frac{\partial P}{\partial S^{I}} \cdot \frac{-\partial C / \partial \bar{\mu}}{C^{4}}\right](1-L / P)-\frac{\partial C}{\partial S^{I}} \cdot \frac{L \cdot \partial P / \partial \bar{\mu}}{C^{2} \cdot P^{2}}\right\} \\
& \propto \Delta^{I}\left\{\left[\begin{array}{ccc}
\frac{\partial^{2} C}{\partial S^{I} \partial \bar{\sigma}}-\frac{\partial P}{\partial S^{I}} \cdot \frac{\partial C / \partial \bar{\sigma}}{C^{2}} \\
(+) & (+) & (+)
\end{array}\right](1-L / P)+\frac{\partial C}{\partial S^{I}} \cdot \frac{L \cdot \partial P / \partial \bar{\sigma}}{P 2}\right\} \\
& +N^{I}\left\{\left[\begin{array}{ccc}
\frac{\partial^{2} C}{\partial S^{I} \partial \bar{\mu}}-\frac{\partial P}{\partial S} \cdot \frac{\partial C / \partial \bar{\mu}}{C^{2}} \\
(-) & (+) & (+)
\end{array}\right](1-L / P)-\frac{\partial C}{\partial S^{I}} \cdot \frac{L \cdot \partial P / \partial \bar{\mu}}{P^{2}}\right\} \\
& <0 \quad \text { if } C \rightarrow 0 \text { because the negative first and third terms in the } \\
& \text { brackets dominate; } \\
& \gtrless 0 \quad \text { if } C \rightarrow \infty \text { because the only the third term in the brackets } \\
& \text { is negative. }
\end{aligned}
$$

Planned Solvency III would lower the slope of an insurer's EPEF (labelled $d \alpha>0$ in Figure 1) if the company has little solvency capital initially, permitting to infer that this type of company will reduce its risk exposure. However, the predicted response of highly capitalized companies may well be the opposite, due to a steepening of its EPEF. See Table 1.

This is the case if $C \rightarrow \infty$ combines with a small premium volume $(P \rightarrow 0)$, as would be typical for a startup that has the backing of an established mother company. 
Table 1. Overview of differences between Basel I, II, and III and Solvency I, II, and planned Solvency III ${ }^{\mathrm{a}, \mathrm{b}}$.

\begin{tabular}{|c|c|c|c|c|}
\hline & Comment & Reference & Comment & Reference \\
\hline $\begin{array}{c}\text { Basel I, } \\
\text { Solvency I }\end{array}$ & $\begin{array}{l}\text { Due to fixed risk weights, the } \\
\text { regulation posits a fixed } \\
\text { relationship between } \\
\text { solvency capital and the level } \\
\text { of solvency. }\end{array}$ & Zweifel et al. & $\begin{array}{c}\partial^{2} C / \partial S^{B} \partial \bar{\mu}<0, \partial^{2} C / \partial S^{B} \partial \bar{\sigma}>0: \text { A higher } \\
\text { solvency level calls for more risk capital but } \\
\text { to a lesser (greater) degree if a higher market } \\
\text { return (volatility) prevails, making positive } \\
\text { net values of the bank (insurer) more (less) } \\
\text { likely. Neglecting these facts, results in a } \\
\text { lower slope of the EPEF } \rightarrow \text { Optimum entails } \\
\text { more volatility, lower solvency. }\end{array}$ & $\begin{array}{c}\text { Table A1, } \\
\text { Equation (15). }\end{array}$ \\
\hline
\end{tabular}

\begin{tabular}{|c|c|c|c|c|}
\hline $\begin{array}{c}\text { Basel II, } \\
\text { Solvency II }\end{array}$ & $\begin{array}{l}\text { For a bank (insurer) who } \\
\text { chooses an internal model, } \\
\text { the relationship between } \\
\text { solvency capital and level of } \\
\text { solvency becomes flexible, } \\
\text { provided the constraint on } \\
\text { solvency level is not binding. }\end{array}$ & $\begin{array}{l}\text { Zweifel et al. } \\
\qquad(2015) \text {. }\end{array}$ & $\begin{array}{l}\text { This flexibility is lost if the constraint on the } \\
\text { solvency level is binding } \rightarrow \text { Basel I applies. }\end{array}$ & $\begin{array}{l}\text { Zweifel et al. } \\
\qquad(2015) \text {. }\end{array}$ \\
\hline $\begin{array}{l}\text { Basel III, } \\
\text { Solvency III }\end{array}$ & $\begin{array}{l}\text { Additionally, now banks } \\
\text { (insurers) are mandated to } \\
\text { take risks emanating from } \\
\text { the capital market into due } \\
\text { account.. }\end{array}$ & & $\begin{array}{c}\partial^{2} C / \partial S^{B} \partial \bar{\mu} \text { and } \partial^{2} C / \partial S^{B} \partial \bar{\sigma} \text { are reinserted in } \\
\text { the EPEF } \rightarrow \text { its slope increases, also due to } \\
\text { decreased leverage } \rightarrow \text { Optimum entails less } \\
\text { volatility, higher solvency (not necessarily for } \\
\text { highly capitalized insurers). }\end{array}$ & $\begin{array}{l}\text { Equations (15), } \\
(20) \text { and (21). }\end{array}$ \\
\hline
\end{tabular}

${ }^{a}$ Provided Solvency III is modeled after Basel III. ${ }^{b}$ EPEF: Endogenous perceived efficiency frontier in $(\mu, \sigma)$-space.

With the removal of the "deformation" of the EPEF caused by Solvency I and II, and an increase in the capital requirement, Solvency III regulation is predicted to induce at least insurers with little solvency capital to move to less volatile asset-liability positions and hence a higher level of solvency. However, this desired effect is not guaranteed in the case of highly capitalized insurance companies; on the contrary, they might take on a riskier position as compared to the no-regulation benchmark, similar to the effects of Solvency I and II.

Finally, note that the parameters determining the EPEF for insurers continue to differ from those of banks. In Equations (18) and (21), $\partial P / \partial S^{I}$, indicating how strongly a premium revenue reacts to an increase in solvency and the loss ratio $(L / P)$ are of great importance to insurers. For banks, the crucial issue is how much the rate paid on deposits decreases in response to a higher solvency level $\left(\partial r_{D} / \partial S^{B}\right.$ in Equations (17) and (20)). These differences argue against regulating the two financial institutions in the same way, as far as their solvency is concerned.

\section{Limitations}

This analysis is subject to a number of limitations. First, the behavioral models might be too simplistic; banks and insurers possibly pursue other objectives than just maximizing their risk-adjusted rates of return. Second, for the $(\mu, \sigma)$-approach adopted in this paper to be compatible with the equilibrium in the capital market, expectations have to be homogenous and all assets should have quoted prices. Third, interpreting Basel III (especially Principle 5) and planned Solvency III in terms of the parameters of the model developed in this article could be inappropriate; the regulators may have used a different theoretical background.

\section{Summary and Conclusions}

This paper was motivated by the fact that Basel III solvency regulation is to be fully implemented by 2027, while Solvency III directed at insurers is in preparation, which raises two questions. (i) Will Basel III and planned Solvency III (which is likely to be modelled after Basel III) be more successful than their predecessors Basel I and II and Solvency I and II, respectively? (ii) Is it appropriate to continue regulating the solvency of banks and 
insurers in the same way? The first question reflects the finding of Zweifel et al. (2015) that Basel I and II may well induce banks to take on more rather than less risk, resulting in a lowering of their solvency level. This was found to also hold for insurers in response to Solvency I and II by Zweifel (2015). The second question is motivated by the fact that the parameters determining the solvency of banks differ from those of importance to insurers.

The basic hypothesis underlying the analysis is that banks' investment divisions (insurers' underwriting and investment divisions, respectively), seek to attain a solvency level that balances the advantage of a lower refinancing cost against the disadvantage of tying capital, which would yield higher returns in other uses. However, this solvency level is too low from a societal point of view because it neglects the fact that insolvency causes substantial external costs. In two simple models of behavior, the divisions maximize the rate of return on capital. A higher level of solvency (defined in terms of $\mathrm{VaR}, \mathrm{EVaR}$, or CVar) lowers the cost of refinancing but causes returns forgone by tying extra capital. The division learns the slope of its endogenous perceived efficiency frontier (EPEF) in $(\hat{\mu}, \hat{\sigma})$-space in the course of three periods. In period 1, exogenous changes in expected returns and in the volatility of returns on the capital market occur. These changes induce adjustments during period 2, predicted by comparative-static analysis. In period 3, previous adjustment acts like an exogenous change, triggering a reallocation of assets. Prior to solvency regulation, this adjustment is found to depend mostly on the fact that the relationship between risk capital and solvency is not stable, but depends on exogenous changes in expected returns and the volatility occurring in the capital market.

The regulations imposed by Basel I and II as well as Solvency I and II are shown to neglect this dependence on market conditions, causing a reduction of the slope of the EPEF. This may well induce senior management to take a more risky position than it would in the absence of regulation. Although an increase in risk goes along with an increase in expected returns, it almost certainly entails a lower degree of solvency. Basel III and planned Solvency III (if modelled after Basel III) correct this deficiency by asking banks and insurers to account for developments in capital markets (called "interest rate risk") in their business strategies, designed to ensure solvency (Principle 5 of Basel III). In addition, imposing a maximum leverage ratio amounts to a higher capital requirement, ceteris paribus, which is shown to reduce the slope of the EPEF and hence is likely to induce senior management to adopt a less risky position in the case of banks, and in the case of insurers with little solvency capital.

Despite the limitations of this paper cited in Section 9, its following insights are likely to prove robust. Basel III differs from its predecessors in that it has scope to enhance the banks' level of solvency. As to planned Solvency $\mathrm{III}^{13}$, the same effect can be expected at least for weakly capitalized insurance companies-presumably the subset at which solvency regulation needs to be directed. A recommendation that can be derived from this paper is that future solvency regulation would be well advised to recognize that it induces adjustments by banks and insurers, which are governed by parameters that differ between banks and insurers, arguing against their uniform regulation.

Funding: This research received no external funding.

Institutional Review Board Statement: Not applicable.

Informed Consent Statement: Not applicable.

Data Availability Statement: Not applicable.

Acknowledgments: The author would like to thank participants in 44th EGRIE Seminar of the European Risk and Insurance Economists, in London (September 2017); the Finance Seminar of the University of Zurich (December 2018), and the 12th International Conference Economies of the Balkan and Eastern European Countries (May 2020, online), for suggestions and criticism. I would also like to thank the Academic Editor and three anonymous referees for their feedback on the paper, which resulted in an improved exposition in several instances.

Conflicts of Interest: The author declares no conflict of interest. 


\section{Appendix A}

Table A1. Assumptions of the two models.

\begin{tabular}{|c|c|c|c|}
\hline \multicolumn{2}{|r|}{ Banks } & \multicolumn{2}{|r|}{ Insurers } \\
\hline $\begin{array}{c}\text { Ba1 } \\
\mu=\bar{\mu}+\hat{\mu} \\
\sigma=\bar{\sigma}+\hat{\sigma}\end{array}$ & $\begin{array}{l}\text { Returns and volatility }(\mu, \sigma) \text { are additive in an } \\
\text { exogenous }(\bar{\mu}, \bar{\sigma}) \text { component determined on the } \\
\text { capital market and an endogenous one. }\end{array}$ & $\begin{array}{l}\quad \operatorname{In} 1 \\
\mu=\bar{\mu}+\hat{\mu} \\
\sigma=\bar{\sigma}+\hat{\sigma}\end{array}$ & $\begin{array}{l}\text { Returns and volatility }(\mu, \sigma) \text { are additive } \\
\text { in an exogenous }(\bar{\mu}, \bar{\sigma}) \text { component } \\
\text { determined on the capital market and an } \\
\text { endogenous one. }\end{array}$ \\
\hline $\begin{array}{c}\mathrm{Ba} 2 \\
\partial C / \partial \bar{\mu}<0\end{array}$ & $\begin{array}{l}\text { The higher returns on the capital market, the less } \\
\text { risk capital is needed to attain a given solvency } \\
\text { level. A positive shock on returns makes positive } \\
\text { net values of the bank more likely, therefore } \\
\text { reducing the need for risk capital. }\end{array}$ & $\partial C / \partial \bar{\mu}<0$ & $\begin{array}{l}\text { The higher returns on the capital market, } \\
\text { the less risk capital is needed to attain a } \\
\text { given solvency level. A positive shock on } \\
\text { returns makes positive net values of the } \\
\text { company more likely, therefore reducing } \\
\text { the need for risk capital. }\end{array}$ \\
\hline $\begin{array}{c}\mathrm{Ba} 3 \\
\partial C / \partial \bar{\sigma}>0\end{array}$ & $\begin{array}{l}\text { The higher the volatility in the capital market, the } \\
\text { more risk capital is needed to attain a given } \\
\text { solvency level. Positive net values of the bank are } \\
\text { less likely, and this must be counteracted by more } \\
\text { risk capital. }\end{array}$ & $\begin{array}{c}\operatorname{In} 3 \\
\partial C / \partial \bar{\sigma}>0\end{array}$ & $\begin{array}{l}\text { The (present value of) premium income } \\
\text { depends negatively on the rate of return } \\
\text { attainable in the capital market because } \\
\text { policyholders now have more favorable } \\
\text { investment alternatives. }\end{array}$ \\
\hline $0<\frac{\mathrm{Ba} 4}{\partial \bar{\mu}}<1$ & $\begin{array}{l}\text { The rate of interest that must be paid on deposits } \\
\text { reacts to an exogenous increase of returns less than } \\
\text { proportionally. Otherwise, the condition } \hat{\mu}>r_{D} \\
\text { for an interior optimum (see Equation (4) again) } \\
\text { would sooner or later be violated. }\end{array}$ & $\operatorname{In} 4 \frac{\partial P}{\partial \bar{\mu}}<0$ & $\begin{array}{l}\text { The (present value of) premium income } \\
\text { depends positively on the volatility of } \\
\text { returns in the capital market because the } \\
\text { insurer now offers a comparatively safe } \\
\text { investment alternative to risk-averse } \\
\text { policyholders. }\end{array}$ \\
\hline $\begin{array}{c}\mathrm{Ba} 5 \\
\frac{\partial r_{D}}{\partial \bar{\sigma}}<0\end{array}$ & $\begin{array}{l}\text { With increased volatility in the market, the bank } \\
\text { can offer less favorable conditions to depositors. }\end{array}$ & $\begin{array}{c}\operatorname{In} 5 \\
\frac{\partial P}{\partial \bar{\sigma}}>0\end{array}$ & $\begin{array}{l}\text { A higher solvency level calls for more } \\
\text { risk capital but to a lesser degree if higher } \\
\text { market returns prevail, making positive } \\
\text { net values of the company more likely. }\end{array}$ \\
\hline $\begin{array}{c}\text { Ba6 } \\
\frac{\partial^{2} r_{D}}{\partial S^{B} \partial \bar{\mu}}<0\end{array}$ & $\begin{array}{l}\text { According to B4, the bank must increase its interest } \\
\text { rate on deposits when market conditions become } \\
\text { more favorable. However, it can afford to adjust to } \\
\text { a lesser degree if its solvency level is high. }\end{array}$ & $\begin{array}{c}\operatorname{In} 6 \\
\frac{\partial^{2} C}{\partial S^{I} \partial \bar{\mu}}<0\end{array}$ & $\begin{array}{l}\text { A higher solvency level calls for more } \\
\text { risk capital, especially when market } \\
\text { volatility is high, making positive net } \\
\text { values of the company less likely. }\end{array}$ \\
\hline $\begin{array}{l}\mathrm{Ba7} \\
\frac{\partial^{2} r_{D}}{\partial S^{B} \partial \bar{\sigma}}< \\
\frac{\partial^{2} r_{D}}{\partial S^{B} \partial \bar{\mu}}<0\end{array}$ & $\begin{array}{l}\text { According to B5, the bank must follow the market } \\
\text { with its interest paid on deposits. However, it can } \\
\text { again afford to adjust to a lesser degree if its } \\
\text { solvency level is high. The inequality derives from } \\
\text { the fact that by } \mathrm{B} 4, \partial r_{D} / \partial \bar{\mu} \text { is bounded, while } \\
\qquad \partial r_{D} / \partial \bar{\sigma} \text { is not. }\end{array}$ & $\begin{array}{c}\operatorname{In} 7 \\
\frac{\partial^{2} C}{\partial S^{I} \partial \bar{\sigma}}>0\end{array}$ & $\begin{array}{l}\text { A higher solvency level calls for more } \\
\text { risk capital, especially when market } \\
\text { volatility is high, making positive net } \\
\text { values of the company less likely. }\end{array}$ \\
\hline $\begin{array}{c}\mathrm{Ba} 8 \\
\frac{\partial^{2} C}{\partial S^{B} \partial \bar{\mu}}<0\end{array}$ & $\begin{array}{c}\text { A higher solvency level calls for more risk capital } \\
\text { but to a lesser degree if higher market returns } \\
\text { prevail, making positive net values of the bank } \\
\text { more likely. }\end{array}$ & $\frac{\operatorname{In} 8}{\partial S^{I} \partial \bar{\mu}}>0$ & $\begin{array}{l}\text { While a higher rate of return on the } \\
\text { capital market depresses premium } \\
\text { income (see In4), this effect weakens if } \\
\text { the insurer offers a high level of solvency. }\end{array}$ \\
\hline $\begin{array}{c}\text { Ba9 } \\
\frac{\partial^{2} C}{\partial S^{B} \partial \bar{\sigma}}>0\end{array}$ & $\begin{array}{l}\text { A higher solvency level calls for more risk capital, } \\
\text { especially when market volatility is high, making } \\
\text { positive net values less likely. }\end{array}$ & $\begin{array}{c}\operatorname{In} 9 \\
\frac{\partial^{2} P}{\partial S^{I} \partial \bar{\sigma}}>0\end{array}$ & $\begin{array}{l}\text { Higher volatility on the capital market } \\
\text { serves to increase premium income (see } \\
\text { In5); this effect is reinforced if the } \\
\text { solvency levels is high. }\end{array}$ \\
\hline
\end{tabular}

\section{Appendix B}

\section{Appendix B.1. Banks}

First, consider a shock $d \hat{\mu}$ disturbing the first-order condition (4). The comparativestatic equation reads,

$$
\frac{\partial^{2} R^{B}}{\partial S^{2}} d S^{B} *+\frac{\partial^{2} R^{B}}{\partial S^{B} \partial \bar{\mu}} d \bar{\mu}=0 \rightarrow \frac{d S^{B} *}{d \bar{\mu}}=-\frac{\frac{\partial^{2} R^{B}}{\partial S^{B} \partial \bar{\mu}}}{\frac{\partial^{2} R^{B}}{\partial S^{B 2}}} .
$$


Since $\partial^{2} R^{B} / \partial S^{B 2}<0$ is in the neighborhood of a maximum, sgn $\left[\partial^{2} R^{B} / \partial S^{B} \partial \bar{\mu}\right]$ determines sgn $\left[d S^{B} * / d \bar{\mu}\right]$. Differentiating Equation (4) w.r.t. $\bar{\mu}$, one has

$$
\frac{\partial^{2} R^{B}}{\partial S^{B} \partial \bar{\mu}}=-\frac{\partial^{2} r_{D}}{\partial S^{B} \partial \bar{\mu}}-\left(\left(1-\frac{\partial r_{D}}{\partial \bar{\mu}}\right) C-\left(\bar{\mu}-r_{D}\right) \frac{\partial C}{\partial \bar{\mu}}\right) \frac{1}{C^{2}} \cdot \frac{\partial C}{\partial S^{B}}-\frac{\bar{\mu}-r_{D}}{C} \cdot \frac{\partial^{2} C}{\partial S^{B} \partial \bar{\mu}} .
$$

Use of the first-order condition (Equation (4)) to obtain $\partial C / \partial S^{B}=-\left(\bar{\mu}-r_{D}\right)^{-1}$ $\left(\partial r_{D} / \partial S^{B}\right) \cdot C$ yields

$$
\begin{gathered}
\frac{\partial^{2} R^{B}}{\partial S^{B} \partial \bar{\mu}}=-\frac{\partial^{2} r_{D}}{\partial S^{B} \partial \bar{\mu}}+\left(1-\frac{\partial r_{D}}{\partial \bar{\mu}}\right) \frac{1}{C} \cdot \frac{1}{\bar{\mu}-r_{D}} C \cdot \frac{\partial r_{D}}{\partial S^{B}}-\left(\mu-r_{D}\right) \frac{\partial C}{\partial \bar{\mu}} \cdot \frac{1}{C^{2}} \cdot \frac{1}{\bar{\mu}-r_{D}} C \cdot \frac{\partial r_{D}}{\partial S^{B}} \\
-\frac{\bar{\mu}-r_{D}}{C} \cdot \frac{\partial^{2} C}{\partial S^{B} \partial \bar{\mu}} .
\end{gathered}
$$

This can be simplified to become Equation (9) of the text.

Now consider $d \bar{\sigma}>0$. In full analogy to (A1), one obtains from Equation (4),

$$
\begin{gathered}
\frac{\partial^{2} R^{B}}{\partial S^{B} \partial \bar{\sigma}}=-\frac{\partial^{2} r_{D}}{\partial S^{B} \partial \bar{\sigma}}-( \\
\left.-\frac{\partial r_{D}}{\partial \bar{\sigma}} \cdot C-\left(\bar{\mu}-r_{D}\right) \cdot \frac{\partial C}{\partial \bar{\sigma}}\right) \cdot \frac{1}{C^{2}} \cdot \frac{\partial C}{\partial S^{B}} \\
-\frac{\bar{\mu}-r_{D}}{C} \cdot \frac{\partial^{2} C}{\partial S^{B} \partial \bar{\sigma}} .
\end{gathered}
$$

Using Equation (4) once again to substitute $\partial C / \partial S^{B}$, one has

$$
\begin{gathered}
\frac{\partial^{2} R^{B}}{\partial S^{B} \partial \bar{\sigma}}=-\frac{\partial^{2} r_{D}}{\partial S^{B} \partial \bar{\sigma}}-\frac{\partial r_{D}}{\partial \bar{\sigma}} \cdot \frac{1}{C} \cdot \frac{1}{\bar{\mu}-r_{D}} C \cdot \frac{\partial r_{D}}{\partial S^{B}}-\left(\mu-r_{D}\right) \frac{\partial C}{\partial \bar{\sigma}} \cdot \frac{1}{C^{2}} \cdot \frac{1}{\mu-r_{D}} C \cdot \frac{\partial r_{D}}{\partial S^{B}} \\
-\frac{\bar{\mu}-r_{D}}{C} \cdot \frac{\partial^{2} C}{\partial S^{B} \partial \overline{\bar{\sigma}}} .
\end{gathered}
$$

Slight rearrangement yields Equation (11) of the text.

Appendix B.2. Insurers

First, consider a shock $d \bar{\mu}$ disturbing the first-order condition (8). The comparativestatic equation reads,

$$
\frac{\partial^{2} R^{I}}{\partial S^{I 2}} d S^{I} *+\frac{\partial^{2} R^{I}}{\partial S^{I} \partial \bar{\mu}} d \bar{\mu}=0 .
$$

In analogy to Equation (A2) the sign of $d S^{I} * / d \bar{\mu}$ is determined by the second-order mixed derivative. Thus,

$$
\begin{aligned}
& \frac{\partial^{2} R^{I}}{\partial S^{I} \partial \bar{\mu}}=\frac{\partial e\left(P, S^{I}\right)}{\partial \bar{\mu}}-\frac{\partial}{\partial \bar{\mu}}\left[e\left(C, S^{I}\right)(1-L / P)\right]=\frac{\partial}{\partial \bar{\mu}}\left[\frac{\partial P}{\partial S^{I}} \cdot \frac{S^{I}}{P}\right]-\frac{\partial}{\partial \bar{\mu}}\left[\frac{\partial C}{\partial S^{I}} \cdot \frac{S^{I}}{C}(1-L / P)\right]
\end{aligned}
$$

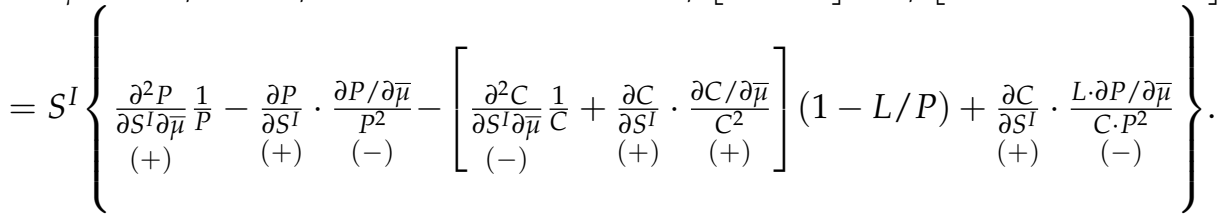

The signs are based on assumptions In9, In4, and In2, as well as Equations (5) and (6). This is Equation (13) of the text.

Now consider $d \bar{\sigma}>0$. In full analogy to (A6), one obtains from Equation (7),

$$
\begin{aligned}
& \frac{\partial^{2} R^{I}}{\partial S^{I} \partial \bar{\sigma}}=\frac{\partial e\left(P, S^{I}\right)}{\partial \bar{\sigma}}-\frac{\partial}{\partial \bar{\sigma}}\left[e\left(C, S^{I}\right)(1-L / P)\right] \\
& =\frac{\partial}{\partial \bar{\sigma}}\left[\frac{\partial P}{\partial S^{I}} \cdot \frac{S^{I}}{P}\right]-\frac{\partial}{\partial \bar{\sigma}}\left[\frac{\partial C}{\partial S^{I}} \cdot \frac{S^{I}}{C}(1-L / P)\right]
\end{aligned}
$$

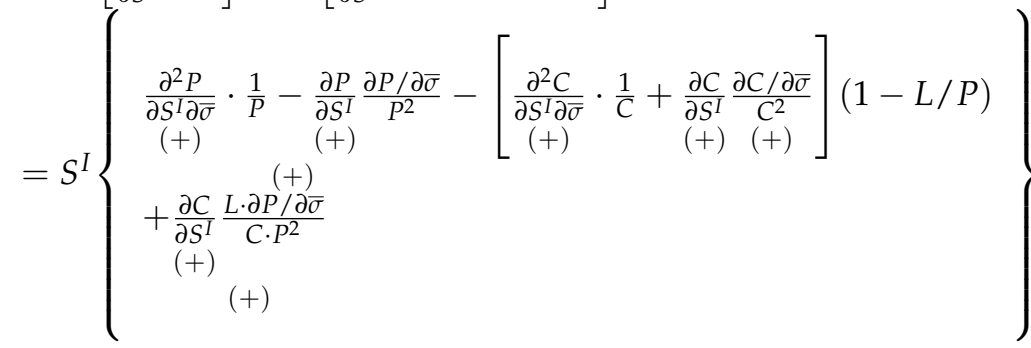


The signs are based on assumptions I9, I5, and I3 of Table A1 as well as Equations (5) and (6) of the text. This is Equation (14) of the text.

Notes

1 The superscript B is dropped whenever there is no risk of confusion.

2 The bracket notation points to the fact that the terms of conditions (4) (and (8), see below) have to be evaluated at some particular values of their arguments. This becomes important in the comparative-static analysis performed in Section 4 below (see also Appendix A).

3 The superscript I is dropped whenever there is no risk of confusion.

4 The financial crisis of 2007-2008 has shown that government bonds are far from risk-free (see e.g., Moody's Investors Service (2010) for a survey of sovereign defaults).

5 The time difference between premiums written and claims paid can be substantial in life insurance, in which case the length of period 0 has to be adjusted accordingly.

6 See Bikker and Gerritson (2017) for empirical evidence.

7 Again, see Bikker and Gerritson (2017) for empirical evidence.

8 Once again, see Bikker and Gerritson (2017) for empirical evidence.

9 In view of the fact that $\sigma$ is a non-convex risk measure that makes it unsuitable for deriving an efficient frontier, Krokhmal et al. (2001) argue in favor of replacing it by the CVar measure. However, since both Basel and Solvency continue to be couched in terms of $\mathrm{VaR}$, banks and insurers would run into conflict with regulation if they derived their EPEF in a different way; indeed Miskolczi (2016) finds that the choice matters.

10 For empirical evidence suggesting that managers act in a risk-averse manner rather than as perfect (i.e., risk-neutral) agents on behalf of (well-diversified) investors, see Milidonis and Stathopoulos (2014) as well as Gormley and Matsa (2016).

11 Over the years, solvency regulation has expanded to include notably liquidity risk (Barth and Miller 2018). However, the maintenance of adequate solvency capital continues to be a concern of crucial importance, justifying this paper's focus on it (Flannery 2014).

12 For more detail on the difference between Solvency I and II, see Zweifel (2015).

13 According to $\mathrm{Ng}$ and Cheung (2015), the authorities of Singapore anticipate Solvency III to closely copy Basel III.

\section{References}

Admati, Anat R., Peter M. DeMarzo, Martin F. Hellwig, and Paul C. Fleiderer. 2013. Fallacies, Irrelevant Facts, and Myths in the Discussion of Capital Regulation: Why baNk Equity Is not Socially Expensive. Working Paper No. 23. Bonn: Max Planck Institute for Research on Collective Goods.

Artzner, Philippe, Freddy Delbaen, Jean-Marc Eber, and David Heath. 1999. Coherent Measures of Risk. Mathematical Finance 9: 203-28. [CrossRef]

Aymanns, Christoph, Carlos Caceres, Christina Daniel, and Liliana Schumacher. 2016. Bank Solvency and Funding Cost. Working Paper No. 16/64. Washington, DC: International Monetary Fund.

Barth, James R., and Stephen Matteo Miller. 2018. On the Rising Complexity of Bank Regulatory Capital requirements: From Global Guidelines to their United States (US) Implementation. Journal of Financial Risk and Management 11: 77. [CrossRef]

Basel Committee on Banking Supervision. 1988. International Convergence of Capital Measurement and Capital Standards. Basel: Bank for International Settlements.

Basel Committee on Banking Supervision. 2004. Basel II: International Convergence of Capital Measurement and Capital Standards: A Revised Framework. Basel: Bank for International Settlements.

Basel Committee on Banking Supervision. 2014. Basel III Leverage Ratio Framework and Disclosure Requirements. Basel: Bank for International Settlements.

Basel Committee on Banking Supervision. 2016. Interest Rate Risk in the Banking Book. Basel: Bank for International Settlements.

Basel Committee on Banking Supervision. 2017. Basel III Transitional Arrangements, 2017-2027. Basel: Bank for International Settlements.

Bauer, Wolfgang, and Mark Ryser. 2004. Risk management strategies for banks. Journal of Banking E Finance 28: 331-52.

Benink, Harald, and George Benston. 2005. The future of banking regulation in developed countries: Lessons from and for Europe. Financial Markets, Institutions $\mathcal{E}$ Instruments 14: 290-328.

Bikker, Jacob A., and Dirk F. Gerritson. 2017. Determinants of interest rates on time deposits and savings accounts: Macro factors, bank risk, and account features. International Review of Finance 18: 169-216. [CrossRef]

Billings, Mark, and Forrest Capie. 2007. Capital in British banking, 1920-1079. Business History 49: 139-62. [CrossRef]

Covitz, Daniel M., Diana Hancock, and Myron L. Kwast. 2004. A reconsideration of the risk sensitivity of U.S. banking organization subordinated debt spreads: A sample selection approach. Economic Policy Review 10: 73-92.

Cummins, J. David, and David J. Nye. 1981. Portfolio optimization models for property-liability insurance companies. An analysis and some extensions, Management Science 27: 414-30.

Cummins, J. David, and David W. Sommer. 1996. Capital and risk in property-liability insurance markets. Journal of Banking and Finance 20: 1069-92. [CrossRef] 
Cummins, J. David, and Mary A. Weiss. 2014. Systemic risk and the U.S. insurance sector. Journal of Risk and Insurance 81: 489-528. [CrossRef]

Cummins, J. David, and Richard D. Phillips. 2001. Applications of financial pricing models for property-liability companies. In Handbook of Insurance. Edited by George Dionne. Norwell: Kluwer, pp. 621-55.

Cummins, J. David. 1988. Risk-based premiums for insurance guaranty funds. Journal of Finance 63: 823-39. [CrossRef]

Diamond, Douglas W., and Philip H. Dybvig. 1983. Bank runs, deposit insurance, and liquidity. Journal of Political Economy 91: 401-19. [CrossRef]

Epermanis, Karen, and Scott E. Harrington. 2006. Market discipline in property/liability insurance: Evidence from premium growth surrounding changes in financial strength ratings. Journal of Money Credit and Banking 38: 1515-44. [CrossRef]

Flannery, Mark J., and Sorin M. Sorescu. 1996. Evidence of bank market discipline in subordinate debenture yields: 1983-1991. Journal of Finance 51: 1347-77.

Flannery, Mark J. 2014. Maintaining Adequate Bank Capital. Journal of Money Credit and Banking 46: 157-80. [CrossRef]

Furfine, Craig H. 2003. Interbank exposures: Quantifying the risk of contagion. Journal of Money, Credit, and Banking 35: 111-28. [CrossRef]

Goldberg, Lawrence G., and Sylvia Hudgins. 1996. Response of uninsured depositors to impending S\&L failures: Evidence of depositor discipline. Quarterly Review of Economics and Finance 36: 311-25.

Goldberg, Lawrence G., and Sylvia C. Hudgins. 2002. Depositor discipline and changing strategies for regulating thrift institutions. Journal of Financial Economics 63: 263-74. [CrossRef]

Gormley, Todd A., and David A. Matsa. 2016. Playing it safe? Managerial preferences, risk, and agency conflicts. Journal of Financial Economics 122: 431-55. [CrossRef]

Harris, Milton, Christian C. Opp, and Marcus M. Opp. 2014. Higher Capital Requirements, Safer Banks? Macroprudential Regulation in a Competitive Financial System. Working Paper. Chicago: University of Chicago Booth School of Business.

Heyde, Chris C., Steven G. Kou, and Xianhua H. Peng. 2006. What Is a Good Risk Measure: Bridging the Gaps between Data, Coherent Risk Measures, and Insurance Risk Measures. Working Paper. New York: Columbia University.

Hogan, Thomas L. 2021. A Review of the Regulatory Impact Analysis of Risk-Based Capital and Related Liquidity Rules. Journal of Risk and Financial Management 14: 24. [CrossRef]

International Monetary Fund. 2013. European Union: Publication of Financial Sector Assessment Program Documentation-Technical Note on Stress Testing of Banks. IMF Country Report No. 13/68. Washington, DC: IMF.

Jacklin, Charles J., and Sudipto Bhattacharya. 1988. Distinguishing panics and information-based bank runs: Welfare and policy implications. Journal of Political Economy 96: 568-92. [CrossRef]

Jensen, Michael C., and William H. Meckling. 1976. Theory of the firm: Managerial behavior, agency costs and ownership structure. Journal of Financial Economics 3: 305-60. [CrossRef]

John, Kose, Anthony Saunders, and Lemma W. Senbet. 2000. A theory of bank regulation and management compensation. Review of Financial Studies 13: 95-125. [CrossRef]

Jordan, John S. 2000. Depositor discipline at failing banks. New England Economic Review, 15-28.

Kim, Daesik, and Anthony Santomero. 1988. Risk in banking and capital regulation. Journal of Finance 43: 1219-33. [CrossRef]

Koehn, Michael, and Anthony Santomero. 1980. Regulation of bank capital and portfolio risk. Journal of Finance 35: 1235-44. [CrossRef]

Krokhmal, Palo, Jonas Palmquist, and Stanislav Urysav. 2001. Portfolio Optimization with Conditional Value-at-Risk Objective and Constraints. Working Paper. Gainesville: University of Florida, Dept. of Industrial and Systems Engineering.

Lang, Larry H.P., and René M. Stulz. 1992. Contagion and competitive intra-industry effects of bankruptcy announcements. Journal of Financial Economics 32: 45-60. [CrossRef]

Leibowitz, Martin, Stanley Kogelman, and Lawrence N. Bader. 1992. Asset performance and surplus control: A dual-shortfall approach. Journal of Portfolio Management 21: 29-37. [CrossRef]

Merton, Robert C. 1974. On the pricing of corporate debt: The risk structure of interest rates. Journal of Finance 29: 449-70.

Merton, Robert C. 1977. An analytical derivation of the cost of deposit insurance and loan guarantees. Journal of Banking $\mathcal{E}$ Finance 1: 3-11.

Milidonis, Andreas, and Konstantinos Stathopoulos. 2014. Managerial incentives, risk aversion, and debt. Journal of Financial and Quantitative Analysis 49: 453-81. [CrossRef]

Miskolczi, Panna. 2016. Differences between mean-variance and mean-cvar portfolio optimization models. Annals of the Faculty of Economics of Oradea University 1: 548-57.

Moody's Investors Service. 2010. Sovereign Default and Recovery Rates 1983-2009. Available online: https://www.moodys.com/

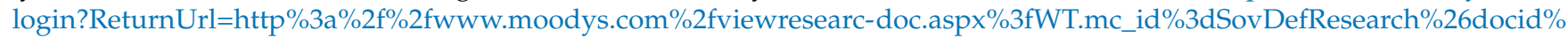
3dPBC_124389\%26lang\%3 (accessed on 7 June 2021).

Mülbert, Peter O. 2009. Corporate governance of banks. European Business Organization Law Review 10: 411-36. [CrossRef]

Nakada, Peter, Hemant Shah, H. Ugur Koyluoglu, and Olivier Collignon. 1999. P\&C RAROC: A catalyst for improved capital management in the property and casualty insurance industry. Journal of Risk Finance 1: 1-18.

Ng, Questor, and Raymond Cheung. 2015. Development of Risk Based Capital Framework in Singapore. Available online: http: / / actuaries.org/FUND/singapore/IndustryUpdateRBCDevelop_Cheung.pdf (accessed on 7 June 2021). 
Park, Sangkyun, and Stavros Peristiani. 1998. Market discipline by thrift depositors. Journal of Money, Credit, and Banking 30: 347-64. [CrossRef]

Power, Michael. 2004. The Risk Management of Everything. Rethinking the Politics of Uncertainty. London: Demos.

Repullo, Rafael. 2004. Capital requirements, market power, and risk-taking in banking. Journal of Financial Intermediation 13: 156-82. [CrossRef]

Rochet, Jean-Charles. 1992. Capital requirements and the behaviour of commercial banks. European Economic Review 36: 1137-78. [CrossRef]

Shiller, Robert J. 2016. Irrational Exuberance, 3nd ed. Princeton: Princeton University Press.

Smith, Clifford W., and René M. Stulz. 1985. The determinants of firms' hedging policies. Journal of Financial and Quantitative Analysis 20: 391-405. [CrossRef]

Stulz, René M. 1996. Rethinking risk management. Journal of Applied Corporate Finance 9: 8-24. [CrossRef]

Van Hulle, Karel. 2018. From Solvency II to Solvency III? Available online: https://www.icir.de/fileadmin/Documents/Policy_ Platform/4_VanHulle.pdf (accessed on 7 June 2021).

Woehrmann, Peter, Willi Semmler, and Martin Lettau. 2004. Nonparametric Estimation of the Time-Varying Sharpe Ratio in Dynamic Asset Pricing Models. Working Paper No. 225. Zurich: University of Zurich, Institute for Empirical Research.

Zweifel, Peter, Dieter Pfaff, and Jochen Kühn. 2015. A simple model of bank behaviour-with implications for solvency regulation. Studies in Microeconomics 3: 49-68. [CrossRef]

Zweifel, Peter, Roland Eisen, and David L. Eckles. 2021. Insurance Economics, 2nd ed. New York: Springer, in print.

Zweifel, Peter. 2015. Solvency regulation of insurers: A regulatory failure? Journal of Insurance Issues 37: 135-57. 